\title{
Productivity and Trade Dynamics in Sudden Stops *
}

\author{
Felipe Benguria $^{\dagger} \quad$ Hidehiko Matsumoto $\ddagger \quad$ Felipe Saffie $\S$
}

February 2019

[Preliminary Version]

Click Here for Most Recent Version

\begin{abstract}
This paper studies productivity and trade dynamics during sudden stop episodes. Sudden stops of capital inflows to emerging economies are characterized by deep recessions, slow recoveries, sharp devaluations, and reversals in the trade balance. We develop a framework to capture these salient features of sudden stops. The model features endogenous productivity and trade dynamics, and endogenous sudden stops. In this environment, firm and product entry and exit into domestic and export markets play a key role in shaping the dynamic response of the economy to a sudden stop. We discipline the model using unique firm-product level data in both domestic and export markets from a census of manufacturing firms in an emerging economy. The calibrated model matches the key stylized facts of sudden stops and their aftermath. In addition, we show that the models' predictions are consistent with the dynamics of firms' product portfolios during the Chilean sudden stop of 1998.
\end{abstract}

Keywords: Endogenous growth, Firm dynamics, Trade dynamics, Sudden Stops.

JEL classification: F10, F41, F43, F44, O33

\footnotetext{
${ }^{*}$ We are grateful to conference participants at LACEA 2018 for insightful comments. All errors are our own.

${ }^{\dagger}$ Department of Economics, University of Kentucky (fbe225@uky.edu).

‡Bank of Japan, (matsumoto@econ.umd.edu).

§ Department of Economics, University of Maryland, (saffie@econ.umd.edu).
} 


\section{Introduction}

Business cycles in emerging economies are characterized by volatile international capital flows, and sudden stops of capital inflows often cause severe economic downturns. These sudden stop episodes are characterized by sharp devaluations, trade balance reversals, and slow recoveries. A key distinctive feature of these events is that the growth slowdown in the aftermath is primarily explained by reduced aggregate productivity growth [Mendoza, 2010]. A second key attribute is that firm and product entry and exit into domestic and export markets play a key role in shaping the dynamic response of the economy. These features suggest that a theory of sudden stops should consider both trade and productivity dynamics, including the response at the extensive margin (firm and product creation). This paper develops a simple and coherent model of sudden stops that can account for these features.

Our model combines a Klette and Kortum [2004] type growth model of endogenous productivity dynamics - extended to an open economy setting - with a leverage-driven model of endogenous sudden stops and an endogenous real exchange rate. We model a small open economy consisting of final and intermediate good producers. Innovation occurs in the intermediate good sector, in which firms produce differentiated varieties, and innovate to introduce domestic or export product lines. This process gives rise to rich endogenous productivity and trade dynamics. Sudden stops are modeled following Mendoza [2010] and Bianchi and Mendoza [2018]. We treat sudden stops as endogenous events because these are low (but positive) probability events. Expectations are essential to firm and product entry, which play a key role in the adjustment and are based on forward looking decisions. In the model, final good producers demand intermediate inputs and a productive asset existing in fixed supply to produce a tradable good. These firms use their productive asset as collateral for borrowing to finance working capital. A collateral constraint is such that firm debt cannot exceed a fraction of the value of this asset. Series of favorable productivity and interest rate shocks cause increases in leverage. Unfavorable shocks arriving at times of high leverage make the collateral constraint binding, raising the effective cost of borrowing and leading to a financial crisis. A sudden stop episode reduces the demand of tradable final good producers for intermediate inputs.

Sudden stops have a starkly different impact on exporters and non-exporters. Exports benefit from a decline in costs due to lower wages and face a stable foreign demand. The extensive margin is driven by innovation to introduce new export lines. This margin adjusts gradually, because most of the depreciation reverts quickly and innovation decisions are forward looking. This is consistent with the empirical evidence in Alessandria et al. [2014]. In contrast, intermediate goods producers selling to the domestic market face a lower demand and earn lower profits. Innovation to introduce new domestic product lines, which drives entry and technological progress, slows down on impact, as the impact on 
domestic demand is fairly persistent. The large and immediate declien in domestic entry matches the empirical evidence documented by Ates and Saffie [2016]. The decline in entry rates to the domestic market generates a persistent effect of sudden stops on productivity and over time, gradual entry into exporting contributes to the recovery.

To discipline the model we introduce novel stylized facts on the dynamics of firm product portfolios. These facts are drawn from a unique Census of Manufactures from an emerging economy - Chile - that lists the entire set of products sold domestically and exported. We document that firms introduce products into the domestic market first, rarely adding them simultaneously to the export market. Products introduced into the export market are most often sold domestically first. When firms drop products from the export market, these transition into being sold solely in the domestic market. Products are rarely drawn from the domestic and export markets simultaneously.

Next we show how firms' existing product portfolios shape the probability with which these transitions are observed. The probability that a firm introduces a product in the domestic market is increasing in the firms' number of existing products. The probability that a firm starts exporting a product previously sold only domestically is increasing in the number of domestically sold products. The probability that a firm drops a product from the domestic market is increasing in the number of domestic products. Finally, the probability of withdrawing a product from the export market to be sold only domestically is increasing in a firm's number of exported products. The model is consistent with these new stylized facts of firms' product portfolio dynamics.

We calibrate the model to a representative emerging economy and show it can replicate the key stylized facts of sudden stop episodes discussed earlier. The model is calibrated using standard macroeconomic ratios as well as microeconomic moments obtained from the dataset of firms' product portfolios described earlier. With the calibrated model, we find that following a sudden stop, the asset price falls by $8 \%$, the debt-to-GDP ratio declines by $1 \%$, GDP declines by $5 \%$ and consumption falls $3.5 \%$ below trend. More importantly, firm and trade dynamics in the simulated model are consistent with the empirical evidence in the literature. First, both entry and incumbent firms' innovation substantially decline during sudden stops. This slows down aggregate productivity growth and in turn leads to a persistent negative impact on GDP, consistent with the empirical findings in Cerra and Saxena [2008] and Blanchard et al. [2015]. Second, while imports of intermediate goods decline, exports of intermediate goods remain unaffected, roughly in line with empirical facts documented in Alessandria et al. [2014]. Moreover, export profits rise by 13\% relative to the trend and stay above-trend several years following a sudden stop. This is due to a decline in the real wage which reduces the marginal cost of production of domestic relative to foreign rival firms. Firms then invest more in innovation to export, 
and the extensive margin of exports expands gradually, which is also consistent with the empirical fact shown in Alessandria et al. [2014].

Guided by the quantitative model, we study the Chilean sudden stop of 1998, showing that these predictions are consistent with the dynamics of firms' product portfolios during this episode. This was a large, unanticipated and exogenous shock to the Chilean economy. In line with the model, the probability that firms introduce domestic products falls during the sudden stop, while the probability of exporting products previously limited to the domestic market falls to a much lesser extent. The probability that a firm drops domestic products rises relative to the probability that a firm withdraws exported products. Finally, revenue obtained from selling domestic products falls relative to revenue from exported products.

The rest of the paper is organized as follows. Section 1.1 reviews the related literature. Section 3 introduces the model. Section 4 presents calibration of the model and the quantitative analysis. Section 5 concludes.

\subsection{Contribution to the Existing Literature}

Our paper contributes to a literature studying the response of the economy to sudden stops. Recent work [Mendoza, 2010, Jeanne and Korinek, 2013, Bianchi, 2011, Bianchi and Mendoza, 2018] models sudden stops as endogenous events using occassionally binding collateral constraints. This approach produces the amplification and asymmetry that these events epitomize, preserving long-run business cycle properties of standard models. Our contribution to this literature is incorporating productivity and trade dynamics, in a heterogeneous-firms framework. This is essential because the slow recovery following these episodes is characterized by slow TFP growth [Mendoza, 2010] and a key role of the extensive margin of exports [Alessandria et al., 2014]. In recent developments in this literature, Seoane and Yurdagul [2017] and Akıncı and Chahrour [2018] introduce growth rate trend shocks and news shocks to improve the quantitative performance of these models. Endogenous technological change generates fluctuations in growth rates with similar properties to news and trend shocks, so by explicitly modeling endogenous trade and productivity dynamics we provide a measurable microfundation for these channels.

Our paper is part of a nascent literature that blends endogenous technological change and international finance with the goal of studying the medium and long-run consequences of large but temporary external shocks. Comin and Gertler [2006] develop a model in which short-run shocks to the economy causes medium-term business cycles using a product-variety expansion type of endogenous growth framework. A similar framework is used by Queralto [2013] to study Korea's 1997 finacial crisis, by 
Guerron-Quintana and Jinnai [2018] to measure the cost of the U.S. Great Recession, by Gornemann [2014] to explain long-term costs of sovereign crises, and by Ma [2017] to study macroprudential policies. Closer to our paper Ates and Saffie [2016] bridge a version of the Schumpeterian growth model of Klette and Kortum [2004] and the business cycle model of Neumeyer and Perri [2005] and Uribe and Yue [2006] to show that sudden stops have a persistent effect on growth through the composition of entering firms. Matsumoto [2018] extends Ates and Saffie [2016] allowing for an occosinally binding constraint to study the interplay of FDI and reserve accumulation in emerging countries. A key contribution of our model to this literature is incorporating trade dynamics, which are essential to the understanding of sudden stops in emerging markets. In addition we contribute to this literature by using microdata on firms' domestic and export product portfolios.

These trade dynamics are important as the literature studying the adjustment of exporters to crises or large devaluations shows. In this regard, Alessandria et al. [2014] show that the sluggish response of exports to large devaluations is driven by the extensive margin, which adjusts slowly given its forward looking nature. Alfaro et al. [2018] find that exporting firms' productivity and innovation rise in response to depreciations. Blaum [2017] shows that the response of imports to devaluations is determined in part by the fact that large exporters - which expand during a devaluation - import inputs to produce. Trade dynamics are in turn key to aggregate productivity. Bernard and Jensen [2004] show that exporters account for a large share of TFP growth in U.S. manufacturing.

We also relate to the literature on endogenous technical change. Recent work has studied the interaction between trade and productivity dynamics (e.g. [Perla et al., 2015, Buera and Oberfield, 2016, Sampson, 2015, Bloom et al., 2013]). The closest to our paper is Akcigit et al. [2018] as they also model competition between intermediate good producers across countries. The link between trade and productivity in our model is more stylized, allowing us to go beyond transitional dynamics studying aggregate risk with occasionally binding financial constraints. On the empirical front we also make a key contribution to the endogenous technical change literature. In fact, the quantitative literature that builds on Klette and Kortum [2004] has relied on patent and plant level data to estimate the parameters governing the expansions and contractions of products [Akcigit and Kerr, 2018, Acemoglu et al., 2018, Lentz and Mortensen, 2008]. In contrast, we observe the portfolio of domestic and exported products at the plant level. Thus, this is the first paper in the Klette and Kortum [2004] framework that uses product level data for calibration and validation. 


\section{New Stylized Facts on the Dynamics of Firms' Product Portfolios}

This section introduces new stylized facts on the dynamics of firms' product portfolios using novel data listing the universe of domestic and export products of Chilean firms in the manufacturing sector. To guide our model, we document the frequency of firms' product transitions and the relationship between the probability of these transitions and the existing basket of firms' products. We establish there is an order in which products are added to or dropped from each market: products are typically introduced first to the domestic market and then to the export market. Products are dropped first from the export to the domestic market and then discontinued. The probability of adding domestic products is increasing in the number of products in a firm's existing portfolio, and the probability of exporting a domestically sold product is increasing in the number of existing domestic products.

\subsection{Data: Firms' Product Portfolios}

We use unique data on firms' product portfolios in an emerging economy. Our firm-product level data comes from the Chilean Annual Survey of Manufactures, which contains data on the universe of manufacturing plants with 10+ employees. While the standard information on plant-level outcomes of this Census has been used extensively in the literature, we have access to an additional form that records each product produced by each firm. This data reports separately domestic and export sales of each of these products. We use annual firm-level product data for 1996-2000. We are able to aggregate the plant level data to the firm level. In addition, we construct firms' ages using the standard plant-level data of this annual Census of Manufactures starting in 1980. This data has been used by Navarro [2012] and Voigtlaender and Garcia-Marin [2018]. To the best of our knowledge, the Chilean Census of Manufactures is the only one reporting firm-product level data and distinguishing between domestic and export markets.

The findings below are based on a balanced panel for 1996-1997 with 3512 firms in which 825 $(23.5 \%)$ are exporters in 1996 and $870(24.8 \%)$ are exporters in 1997. This panel excludes firms in metallic (primarily copper) industries which are closer to the commodity sector than manufacturing. ${ }^{1}$

\subsection{Empirical Findings}

FINDING 1: Products introduced to the domestic market are typically not exported beforehand. Products introduced to the export market have typically been sold domestically before. Products withdrawn from the

\footnotetext{
${ }^{1}$ Our results are very similar if we include these industries.
} 
domestic market are typically not being exported. Products withdrawn from the export market are typically then sold domestically.

Our first finding refers to the frequency with which firms add or drop products from the domestic and export markets. Based on our balanced 1996-1997 panel we count the number of firms adding or dropping products and group them according to their initial and final status (not sold, sold exclusively domestically, or exported). We define six transitions of interest. The frequency of these transitions is shown in Column 1 in Table 1 . We find that $15.4 \%$ of firms add one or more domestic product not produced the previous year. $2.6 \%$ of firms add one or more new products simultaneously to the domestic and export markets. We also find that $5.3 \%$ of firms add one or more products to the export market sold exclusively in the domestic market the previous year.

We also find that $16.0 \%$ of firms drop one or more domestic products. $2.7 \%$ of firms drop one or more product both sold domestically and exported. Finally, 4.5\% of firms drop one or more products from the export market that transitions to be sold only domestically the next period.

FINDING 2: The distribution of the number of products added or dropped by firms is skewed.

We document the distribution of the number of products added or dropped in each transition in Table 1. In each case, there is a larger probability of adding or dropping a single product, and the probability of each event is decreasing in the number of products added or dropped. In all cases, the decrease in the probability of adding or dropping a single product to adding or dropping more than one is quite steep. For instance, while $10 \%$ of firms introduce a new product to the domestic market, only $3 \%$ introduce 2 products and 3\% introduce three or more; and while $5 \%$ introduce a single product previously sold domestically to the export market, only $0.4 \%$ introduce two, and $0.4 \%$ introduce three or more.

FINDING 3: The probability that a firm introduces a product to the domestic market is increasing in the firm's total number of products. The probability that a firm adds a domestically sold product to the export market is increasing in the firm's total number of domestic products. The probability that a firm withdraws a product from the domestic market is increasing in the firm's total number of domestic products. The probability that an exporting firm withdraws a product from the export market, selling it only domestically, is increasing in the firm's total number of exported products.

Our third finding documents how a firm's existing product portfolio shapes the addition or removal of products from the domestic and export markets. To this end, equation 1 estimates the impact of the 
existing number of products on the probability that each of the transitions described in Table 1 takes place. We restrict our analysis to the transitions that were established to occur more frequently (i.e. the first four transitions in Table 1). In this equation, $Y_{f}$ is a dummy variable taking a value of one if a transition takes place and zero otherwise. $X_{f}$ represents measures of the existing number of products. Our regression includes firm age as an additional control. It also includes industry $(s)$ fixed effects (at the four-digit level of disaggregation) in order to compare across firms within a given industry). Given the inclusion of fixed effects, we estimate this equation using a linear probability model. Similar results are obtained estimating a probit model.

$$
Y_{f}=\beta_{1} \cdot X_{f}+\beta_{2} \cdot \operatorname{Age}_{f}+\phi_{s}+\epsilon_{f}
$$

The results are shown in Table 2. For each of the different transitions in Columns 1 through 4 , the regressor $X_{f}$ varies, as we are interested in choosing the regressor that speaks directly to the model in Section 3. Column 1 indicates that one additional product produced by a firm in period $t$ is associated to a 1.6 percentage point increase in the probability that a firm introduces one or more new domestic products between periods $t$ and $t+1$. This coefficient is relatively large, as the unconditional probability of adding new domestic product (shown in the first row of Table 1 ) is 0.15 . Column 2 indicates that one additional domestic product sold by a firm in period $t$ leads to a 0.6 percentage point increase in the probability that a firm introduces a new domestic product between periods $t$ and $t+1$. Column 3 shows that one additional domestic product sold by a firm in period $t$ is associated to a 6.6 percentage point increase in the probability that a firm drops a domestic product between periods $t$ and $t+1$. Finally Column 4, which is restricted to firms that export in $t$, shows that one additional exported product sold by a firm in period $t$ is associated to a 4.9 percentage point increase in the probability that a firm drops an exported product (subsequently sold only domestically) between periods $t$ and $t+1$. In most cases, firm age seems to be uncorrelated with the probability of adding or dropping products once we control for the existing number of products. 
Table 1: Number of Firms Per Transition

\begin{tabular}{lcccc}
\hline \hline & \multicolumn{4}{c}{ Number of Products Added OR Dropped } \\
& Any & 1 & 2 & $3+$ \\
\hline & & & & \\
Not Produced to Domestic & 0.15 & 0.10 & 0.03 & 0.03 \\
Domestic to Exported & 0.05 & 0.05 & 0.004 & 0.004 \\
Domestic to Not Produced & 0.16 & 0.10 & 0.03 & 0.03 \\
Exported to Domestic & 0.05 & 0.04 & 0.005 & 0.003 \\
Not Produced to Domestic + Exported & 0.03 & 0.02 & 0.003 & 0.002 \\
Domestic + Exported to Not Produced & 0.03 & 0.02 & 0.004 & 0.001 \\
& & & & \\
\hline \hline
\end{tabular}

Note: This table reports the frequency of firms' product transitions. The transitions in each row are (1) a firm introduces to the domestic market a product not sold previously, (2) a firm introduces to the export market a product previously sold domestically, (3) a firm withdraws a product from the domestic market, subsequently not selling it, (4) a firm withdraws a product from the export market, subsequently selling it domestically, (5) a firm introduces simultaneously to the domestic and export market a product not sold previously, and (6) a firm simultaneously withdraws a product from the domestic and export markets, subsequently not selling it.

Table 2: Transitions and Firm Characteristics

\begin{tabular}{|c|c|c|c|c|}
\hline & $\begin{array}{c}(1) \\
\text { Not Produced } \\
\text { to } \\
\text { Domestic }\end{array}$ & $\begin{array}{c}(2) \\
\text { Domestic } \\
\text { to } \\
\text { Exported }\end{array}$ & $\begin{array}{c}(3) \\
\text { Domestic } \\
\text { to } \\
\text { Not Produced }\end{array}$ & $\begin{array}{c}(4) \\
\text { Exported } \\
\text { to } \\
\text { Domestic }\end{array}$ \\
\hline Number of Products & $\begin{array}{c}0.016^{* * *} \\
(0.002)\end{array}$ & & & \\
\hline Number of Domestic Products & & $\begin{array}{c}0.006^{* * *} \\
0.002\end{array}$ & $\begin{array}{c}0.066^{* * *} \\
0.002\end{array}$ & \\
\hline Number of Exported Products & & & & $\begin{array}{l}0.049^{* * *} \\
(0.012)\end{array}$ \\
\hline Age $(\log )$ & $\begin{array}{c}0.000 \\
(0.007)\end{array}$ & $\begin{array}{l}0.010^{* *} \\
(0.005)\end{array}$ & $\begin{array}{c}0.005 \\
(0.007)\end{array}$ & $\begin{array}{l}-0.016 \\
(0.019)\end{array}$ \\
\hline Observations & 3503 & 3503 & 3503 & 809 \\
\hline
\end{tabular}

Note: This table reports the results of the estimation of equation 1 . The dependent variable in each column is (1) the probability that a firm introduces to the domestic market a product not sold previously, (2) the probability that a firm introduces to the export market a product previously sold domestically, (3) the probability that a firm withdraws a product from the domestic market, subsequently not selling it, and (4) the probability that a firm withdraws a product from the export market, subsequently selling it domestically. 


\section{Model}

The model consists of an infinite-horizon small open economy. A representative firm produces a tradable final good. This firm borrows working capital within each period and faces an endogenous collateral constraint. Shocks to aggregate productivity and the real interest rate can occassionally make this constraint binding and generate sudden stops.

A set of firms produce differentiated intermediate varieties used to assemble the final good in the domestic market or abroad. This intermediate sector is modeled as a version of the Schumpeterian growth model developed by Ates and Saffie [2016], which is a discrete time version of Klette and Kortum [2004] incorporating aggregate risk. These intermediate good producers innovate to introduce new product lines, competing among them and with foreign firms to become the lowest cost producer under Bertrand competition. These firms also innovate to be able to export these product lines. This setting in the intermediate sector generates endogenous productivity dynamics. In addition it gives rise to trade dynamics at the intensive and extensive margins. A nontradable sector allows for an endogenous real exchange rate. An overview of this environment is presented in Figure 1.

Figure 1: Model Economy

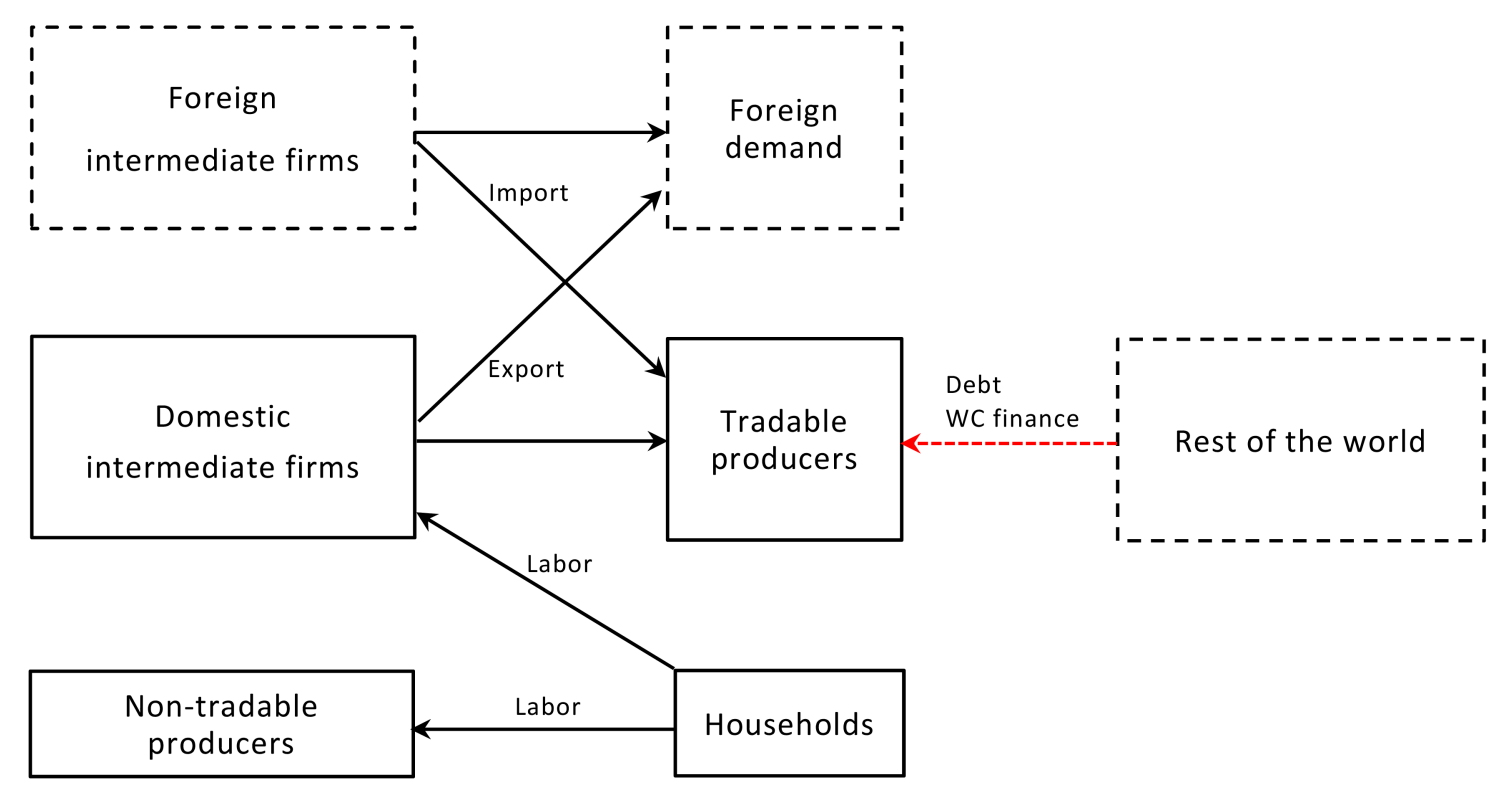

Note: This figure represents the structure of the model. 


\subsection{Tradable Final Good}

A representative firm produces a tradable final good using a set of differentiated intermediate goods $\left\{y_{t}(i)\right\}_{i=0}^{1}$ according to the production function:

$$
Y_{t}^{T}=\exp \left(\varepsilon_{t}^{A}\right) \exp \left[\int_{0}^{1} \ln y_{t}(i) d i\right]
$$

in which $\varepsilon_{t}^{A}$ is a stochastic productivity shock.

We assume the firm must pay in advance a fixed fraction $\phi$ of the cost of intermediate inputs. This working capital payment is financed by within-period borrowing from abroad without any interest. In addition, the firm borrows from abroad using a one-period non-contingent bond. The firm is subject to the following collateral constraint, which states that total borrowing must not be larger than a fixed fraction $\kappa$ of the value of a productive asset owned by the firm and used as collateral.

$$
-B_{t}+\phi\left[\int_{0}^{1} p_{t}(i) y_{t}(i) d i\right] \leq \kappa Q_{t} L_{t-1}
$$

In this expression $Q_{t}$ denotes the price of the asset and $L_{t-1}$ denotes the amount owned by the firm. The firm rents this productive asset at a rate $R_{t}^{L}$ to firms in the intermediate good sector, which require it to produce. This asset exists in fixed supply, which is normalized to one. Each period, the firm chooses amounts of each intermediate good $\left\{y_{t}(i)\right\}_{i=0}^{1}$, the amount of the productive asset $L_{t}$ to hold, and foreign bond holdings $B_{t}$ to maximize the discounted value of current and future profits:

$$
\max _{\left\{\left\{y_{t}(i)\right\}_{i=0}^{1}, L_{t}, B_{t}\right\}_{t=0}^{\infty}} E_{o} \sum_{t=0}^{\infty} \beta^{t} \lambda_{t} \Pi_{t}^{T}
$$

subject to the collateral constraint (3). Future profits are discounted with the same discount rate used by the representative household. ${ }^{2}$ Firm profits are:

$$
\Pi_{t}^{T}=Y_{t}^{T}-\int_{0}^{1} p_{t}(i) y_{t}(i) d i-B_{t}+\exp \left(\varepsilon_{t-1}^{R}\right) R B_{t-1}-Q_{t} L_{t}+\left(Q_{t}+R_{t}^{L}\right) L_{t-1}
$$

where $\lambda_{t}$ is the marginal utility of tradable goods consumption by households, $p_{t}(i)$ is the price of intermediate good $i$, and $\exp \left(\varepsilon_{t}^{R}\right) R$ is a stochastic gross interest rate on the foreign bond. Each period, the final tradable producer chooses intermediate goods demand $\left\{y_{t}(i)\right\}_{i=0}^{1}$, productive asset holdings $L_{t}$, and foreign bond holdings $B_{t}$ to maximize the expected profit discounted by household's discount rate

\footnotetext{
${ }^{2}$ The assumption that the firm can own an asset and can borrow from abroad instead of households makes the problem more tractable. A model in which households own the asset and borrow from abroad would be equivalent but less tractable.
} 
adjusted by the marginal utility $\lambda_{t}$. The demand for each intermediate good is:

$$
p_{t}(i)\left(1+\phi \frac{\mu_{t}}{\lambda_{t}}\right)=\frac{Y_{t}^{T}}{y_{t}(i)}
$$

In this expression, $\mu_{t}$ stands for the Lagrange multiplier on the borrowing constraint (3). When the borrowing constraint is slack, $\mu_{t}=0$ and the demand function for intermediate goods (5) is standard, equating price and marginal product. When the borrowing constraint binds, a strictly positive $\mu_{t}$ appears as the external financing premium on working capital payments, which increases the effective cost of inputs.

\subsection{Intermediate Goods}

There is a continuum of differentiated tradable intermediate goods indexed by $i \epsilon[0,1]$ used to assemble the final good. We refer to these as product lines. These intermediate goods can be produced by domestic or foreign firms. Each product line is produced by a single firm - the lowest cost producer - in a context of Bertrand competition.

These intermediate good producers have heterogeneous productivity levels $a_{t}$. They produce using the productive asset $\left(\ell_{t}\right)$ and labor $\left(h_{t}\right)$ according to the following production function: ${ }^{3}$

$$
y_{t}=a_{t}\left(\ell_{t}\right)^{\alpha}\left(h_{t}\right)^{1-\alpha}
$$

Firms innovate to introduce new product lines by becoming the lowest cost producers. When a firm carries on a succesful innovation, it obtains a productivity lead of an exogenous magnitude, equal to $\left(1+\sigma^{D}\right)$ times the previous leading technology, which becomes available to all firms. Firms also innovate to export existing domestic product lines. When a firm carries on a successful export innovation it obtains a larger productivity lead equal to $\left(1+\sigma^{X}\right)$ the previous existing technology. For each product line, only one successful innovation occurs at a time. The probability of successful innovations and the investment firms need to incur in to innovate are discussed in the next subsection.

Product lines can be classified into domestic lines (D) (in which the lowest cost producer is a domestic firm), export lines (X) (in which a domestic firm has innovated to be able to sell the product both domestically and abroad) and import lines (M) (in which the lowest cost producer is a foreign firm and the final tradable good producer imports the product). We describe prices and profits for each of these three types below.

Under Bertrand competition, the firm with the leading technology sets a price equal to that of the

\footnotetext{
${ }^{3}$ Both factors of production - the productive asset and labor - are internationally immobile
} 
marginal cost of its competitors which have the second-best (i.e. the previous leading) technology. Firms' marginal cost depends on factor prices and trade costs (both of which differ between domestic and foreign firms), and their productivity. ${ }^{4}$

Foreign firms trying to sell in the domestic market face an iceberg trade cost such that, shipping $1+\xi$ units is required to sell 1 unit. Domestic firms trying to sell abroad face the same iceberg trade cost.

(D) Domestic lines In this case the second lowest marginal cost belongs to domestic firms. Because all domestic firms face the same factor prices, differences in cost between the leading firm and its competitors are due only to differences in productivity. Let $a_{t}(i)$ denote the productivity level of the lowest cost producer for line $i$. The price set is equal to the second lowest marginal cost:

$$
p_{t}^{D}(i)=\widetilde{M C}_{t}^{D}(i)=\frac{1}{a_{t}(i) /\left(1+\sigma^{D}\right)} \bar{\alpha}\left(R_{t}^{L}\right)^{\alpha}\left(W_{t}\right)^{1-\alpha}
$$

where $\bar{\alpha}=\alpha^{-\alpha}(1-\alpha)^{-(1-\alpha)}$. Profits obtained from this line are:

$$
\pi_{t}^{D}(i)=p_{t}(i) y_{t}(i)-R_{t}^{L} \ell_{t}(i)-W_{t} h_{t}(i)
$$

Replacing in this expression the demand for intermediate goods by the final tradable good producer (5), profits can be written as:

$$
\pi_{t}^{D}=Y_{t}^{T} \frac{1}{1+\phi \mu_{t} / \lambda_{t}} \frac{\sigma^{D}}{1+\sigma^{D}}
$$

The following points are worth mentioning. First, profits are independent of the productivity level $a_{t}(i)$ of the lowest cost producer. ${ }^{5}$ Second, profits are a decreasing function of the Lagrange multiplier on the borrowing constraint $\mu_{t}{ }^{6}$ Third, profits are independent of factor prices. Factor prices impact both the cost and the price (which is equal to the cost of the second-best firm), cancelling out.

(X) Export lines Export lines are owned by domestic firms and sold both domestically and abroad. In the domestic market, prices and profits are identical to those discussed above for domestic lines, with the only difference that the productivity lead is $\left(1+\sigma^{X}\right)$ :

$$
p_{t}^{X}(i)=\widetilde{M C}_{t}^{X}(i)=\frac{1}{a_{t}(i) /\left(1+\sigma^{X}\right)} \bar{\alpha}\left(R_{t}^{L}\right)^{\alpha}\left(W_{t}\right)^{1-\alpha}
$$

\footnotetext{
${ }^{4}$ Factor prices are a rental rate $R_{t}^{L}$ for the productive asset and wage $W_{t}$. These are denoted $R_{t}^{L *}$ and $W_{t}^{*}$ in the case of foreign firms.

${ }^{5}$ In Appendix A.1 we show that asset and labor inputs for each product line are also independent of productivity. This property enables us to study the aggregate dynamics of the economy without keeping track of heterogeneous productivity levels across product lines.

${ }^{6}$ When the borrowing constraint binds, $\mu_{t}$ is strictly positive and profits decline. The reason for this is that when the borrowing constraint binds, the final tradable good producer lowers its demand for intermediate goods. This translates into lower profits for intermediate good producers.
} 


$$
\pi_{t}^{X}=Y_{t}^{T} \frac{1}{1+\phi \mu_{t} / \lambda_{t}} \frac{\sigma^{X}}{1+\sigma^{X}}
$$

Due to the larger productivity lead, prices in the domesitc market are lower and profits from domestic sales are larger than those of domestic lines.

In the foreign market, a representative final tradable good producer demands intermediate goods according to the following production function:

$$
Y_{t}^{*}=\exp \left[\int_{0}^{1} \ln y_{t}^{*}(i) d i\right]
$$

Foreign production of the final tradable good is not subject to shocks, and $Y_{t}^{*}$ grows at a constant rate. The demand of this foreign final good producer for each intermediate good is:

$$
p_{t}^{*}(i)=\frac{Y_{t}^{*}}{y_{t}^{*}(i)}
$$

In the case of export lines, the second lowest marginal cost belongs to foreign intermediate good producers. The price set for export lines in the foreign market is equal to this second lowest marginal cost:

$$
p_{t}^{*}(i)=\widetilde{M C}_{t}^{*}(i)=\frac{1}{a_{t}(i) /\left(1+\sigma^{X}\right)} \bar{\alpha}\left(R_{t}^{L *}\right)^{\alpha}\left(W_{t}^{*}\right)^{1-\alpha}
$$

Using the expression for the foreign demand for intermediate goods (in equation (11)), profits from export lines' sales abroad are:

$$
\pi_{t}^{*}=Y_{t}^{*}\left(1-\frac{1+\xi}{1+\sigma^{X}} \frac{\left(R_{t}^{L}\right)^{\alpha}\left(W_{t}\right)^{1-\alpha}}{\left(R_{t}^{L *}\right)^{\alpha}\left(W_{t}^{*}\right)^{1-\alpha}}\right)
$$

Profits from export sales differ from profits from domestic sales of export lines in that they do depend (negatively) on factor prices. Lower domestic factor prices make domestic production cheaper, while the export price is determined by foreign factor prices.

(M) Import lines In this case the lowest cost producer is a foreign firm and the domestic final good producer imports the intermediate good, As the demand for intermediate goods by this producer (in equation (5)) has a unit elasticity, the total payment to foreign firms is independent of the price charged:

$$
p_{t}(i) y_{t}(i)=\frac{Y_{t}^{T}}{1+\phi \mu_{t} / \lambda_{t}}
$$

The price is equal to the second lowest marginal cost, which in this case belongs to a domestic firm . The productivity lead by foreign firms is the same as that of domestic exporting firms, $1+\sigma^{X}$. 
Consequently the price is the same as that of export lines in equation (9). Note that in equation (14), the right hand side is independent of a product line $i$ so output $y_{t}(i)$ is also the same as for export lines.

\subsection{Innovation and Firm Dynamics}

Firm dynamics are shaped by firm entry, innovation by incumbent domestic firms, and innovation by foreign firms. The productivity of each product line evolves with each technological improvement generated by successful innovations. A successful domestic innovation increases the existing productivity of a product line by an exogenous factor $1+\sigma^{D}$ and leads an entering or incumbent domestic firm to acquire the product line. An successful export innovation increases the existing productivity of a product line by an exogenous factor $1+\sigma^{X}$ and allows the firm to sell the product domestically and abroad.

Due to entry and innovation, aggregate productivity in the intermediate sector increases over time. Firm dynamics change the status of each product line over time and endogenously determine the extensive margins of imports and exports. Below we explain in detail firms' innovation decisions.

A Graphic Example Figure 2 illustrates an example of the evolution of firms' product lines from a period $t$ to $t+1$. In period $t$ (top panel) domestic firm 1 produces two domestic product lines. Domestic firm 2 produces two domestic and one export lines. There is also one foreign product line. In period $t+1$ (bottom panel) domestic firm 1 succeeds in an exporting innovation for product line 1, which becomes an export line. Domestic firm 1 also succeeds in a domestic innovation and acquires domestic product line 3. Foreign innovation occurs in product line 5, so domestic firm 2 loses that product line. Domestic firm entry is not depicted in the figure.

\subsubsection{Innovation by Incumbent Domestic Firms}

Domestic innovation A firm owning $n^{D}$ domestic lines and $n^{X}$ export lines has $n^{D}+n^{X}$ domestic innovation opportunities. The underlying assumption is that a domestic innovation is a spin-off from existing technologies. For each innovation opportunity, a firm chooses to invest an amount $Z_{t}^{D} \cdot{ }^{7}$ The probability of success of a domestic innovation is proportional to the amount invested:

$$
i_{t}^{D}=\eta^{D}\left(\frac{Z_{t}^{D}}{A_{t}}\right)^{1 / \rho}
$$

This probability is inversely proportional to the average productivity of intermediate firms where $A_{t}$ is (including foreign firms). The functional form is consistent with Akcigit and Kerr [2018], who argue it is consistent with empirical patterns.

\footnotetext{
${ }^{7}$ This investment is measured in units of the tradable final good.
} 

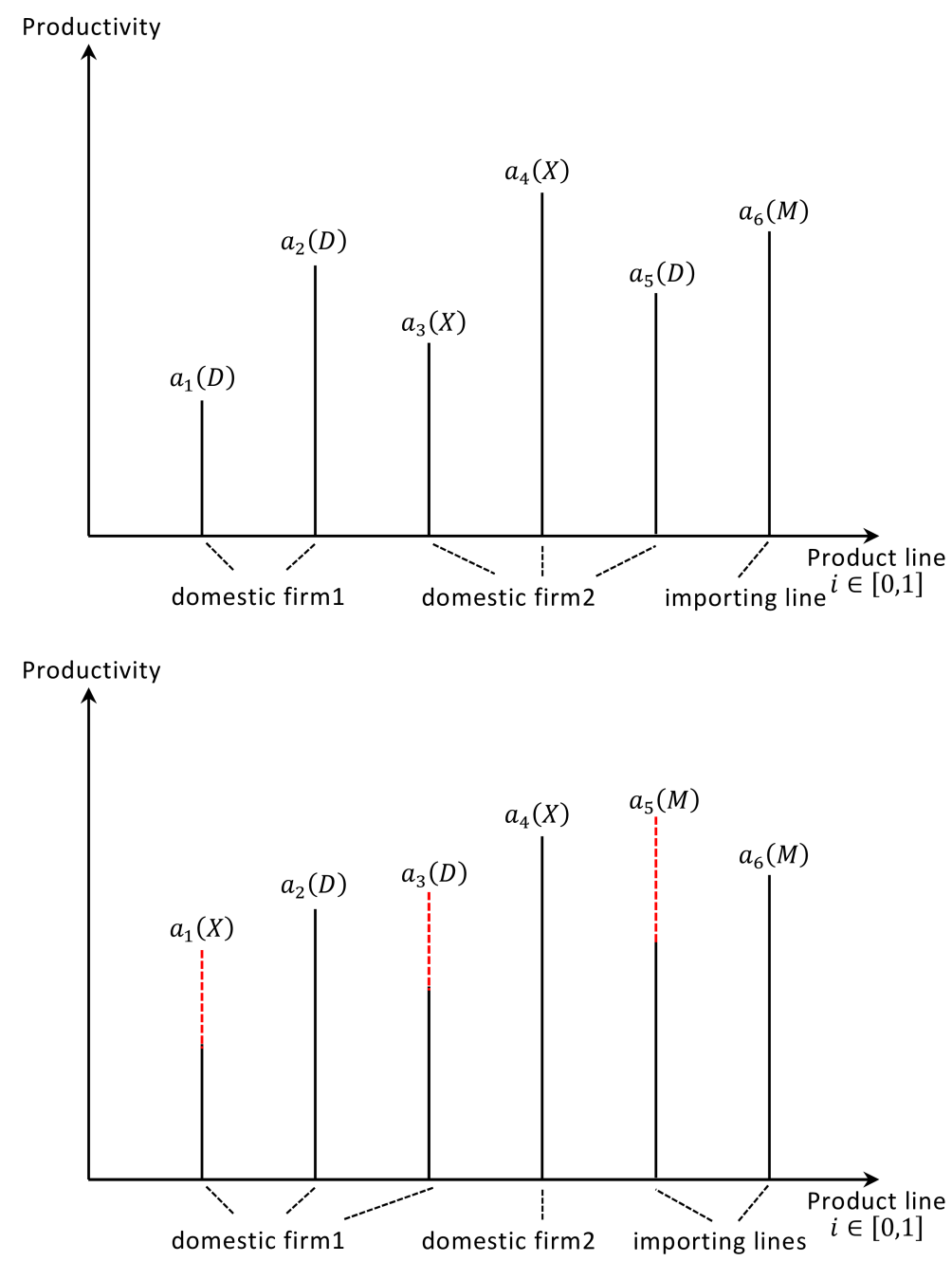

Figure 2: Firm Dynamics

Note: This figure provides an example of firms' product dynamics between an initial period $t$ (top panel) and a subsequent period $t+1$ (bottom panel).

Export innovation A firm owning $n^{D}$ domestic product lines has $n^{D}$ export innovation opportunities. For each innovation opportunity, a firm chooses to invest an amount $Z_{t}^{X}$. The probability of success of an export innovation is:

$$
i_{t}^{X}=\eta^{X}\left(\frac{Z_{t}^{X}}{A_{t}}\right)^{1 / \rho}
$$

When a firm's export innovation is successful, a product sold domestically can also be exported and the domestic line becomes an export line.

Foreign innovation Finally, a foreign firm generates a successful innovation with an exogenous probability $i^{F}$. 


\section{Incumbents' Innovation Decisions}

As is common in Schumpeterian growth models, innovation is undirected in the sense that innovation is equally likely to apply to any product line. This feature is preserved in this model because operating profits are independent of a firm's productivity level, so firms with a given productivity are indifferent among the many product lines that can be introduced. Undirected innovations carried on by many firms imply that each product line faces the same replacement probability $d_{t}$. The probability of $i$ successes in $n$ trials for a binomial process with success probability $p$ is:

$$
P(i, n, p)=\left(\begin{array}{c}
n \\
i
\end{array}\right) p^{i}(1-p)^{1-i}
$$

The value of a domestic firm with $n^{D}$ domestic lines and $n^{X}$ exporting lines can be written in a recursive form as follows:

$$
\begin{aligned}
V_{t}\left(n^{D}, n^{X}\right)= & \max _{Z_{t}^{D}, Z_{t}^{X}}\left\{n^{D} \pi_{t}^{D}+n^{X}\left(\pi_{t}^{X}+\pi_{t}^{*}\right)-\left(n^{D}+n^{X}\right) Z_{t}^{D}-n^{D} Z_{t}^{X}\right. \\
+ & \sum_{i=0}^{n^{D}+n^{X}} P\left(i, n^{D}+n^{X}, i_{t}^{D}\right) \sum_{j=0}^{n^{D}} P\left(j, n^{D}, d_{t}\right) \sum_{k=0}^{n^{D}-j} P\left(k, n^{D}-j,\left(1-d_{t}\right) i_{t}^{X}\right) \sum_{m=0}^{n^{X}} P\left(m, n^{X}, d_{t}\right) \\
& \left.E_{t}\left[\Lambda_{t, t+1} V_{t+1}\left(n^{D}+i-j-k, n^{X}+k-m\right)\right]\right\}
\end{aligned}
$$

The first line represents operating profits minus innovation investment costs. The second and third line add up the expected value of a firm across all the possible combinations of innovations and replacement on $n^{D}$ domestic lines and $n^{X}$ exporting lines in the next period. The first summation adds up across all the possibilities for domestic innovations from 0 success to $n^{D}+n^{X}$ successes. The second summation adds up over the number of domestic lines being replaced from 0 to $n^{D}$. The third summation adds up over the number of successful exporting innovations. We assume that exporting innovations materialize only if replacement does not happen on that line. Thus the effective success probability is given by $\left(1-d_{t}\right) i_{t}^{X}$. The last summation adds up over the number of exporting lines being replaced from 0 to $n^{X}$.

We use a guess-and-verify method to show that the value of a firm with $n^{D}$ domestic lines and $n^{X}$ exporting lines is equal to the sum of $n^{D}$ times the value of a single domestic line and $n^{X}$ times the value of a single exporting line:

$$
V_{t}\left(n^{D}, n^{X}\right)=n^{D} V_{t}(1,0)+n^{X} V_{t}(0,1)
$$

The proof is left to the Appendix. This linear relation enables us to aggregate firm dynamics in a 
tractable way and study how firm dynamics affect endogenous growth and the extensive margins of imports and exports. It enables us to do so without having to keep track of the firm size distribution. The value of a single domestic line is given by:

$$
\begin{aligned}
V_{t}(1,0)= & \max _{Z_{t}^{D}, Z_{t}^{X}}\left\{\pi_{t}^{D}-Z_{t}^{D}-Z_{t}^{X}\right. \\
& \left.+\left(i_{t}^{D}+\left(1-d_{t}\right)\left(1-i_{t}^{X}\right)\right) E_{t}\left[\Lambda_{t, t+1} V_{t+1}(1,0)\right]+\left(1-d_{t}\right) i_{t}^{X} E_{t}\left[\Lambda_{t, t+1} V_{t+1}(0,1)\right]\right\}
\end{aligned}
$$

and the value of a single exporting product line is:

$$
V_{t}(0,1)=\max _{Z_{t}^{D}}\left\{\pi_{t}^{X}+\pi_{t}^{*}-Z_{t}^{D}+i_{t}^{D} E_{t}\left[\Lambda_{t, t+1} V_{t+1}(1,0)\right]+\left(1-d_{t}\right) E_{t}\left[\Lambda_{t, t+1} V_{t+1}(0,1)\right]\right\}
$$

The first-order condition with respect to $Z_{t}^{D}$ pins down the optimal investment for domestic innovation opportunities:

$$
\eta^{D} \frac{1}{\rho}\left(\frac{Z_{t}^{D}}{A_{t}}\right)^{1 / \rho-1} \frac{1}{A_{t}} E_{t}\left[\Lambda_{t, t+1} V_{t+1}(1,0)\right]=1
$$

The first-order condition with respect to $Z_{t}^{X}$ pins down the optimal investment for export innovation opportunities:

$$
\left(1-d_{t}\right) \eta^{X} \frac{1}{\rho}\left(\frac{Z_{t}^{X}}{A_{t}}\right)^{1 / \rho-1} \frac{1}{A_{t}}\left(E_{t}\left[\Lambda_{t, t+1} V_{t+1}(0,1)\right]-E_{t}\left[\Lambda_{t, t+1} V_{t+1}(1,0)\right]\right)=1
$$

Note that investment is forward-looking in the sense that as the expected value of a product line increases, firms increase their investment.

\subsubsection{Domestic Entry}

Entry by domestic firms results from innovation by households. New domestic firms poach a product line from incumbent firms, and start with a single domestic line. Households invest an amount $Z_{t}^{E}$ to create new firms. ${ }^{8}$ The number of firms created from $Z_{t}^{E}$ units of investment is:

$$
e_{t}=\eta^{E}\left(\frac{Z_{t}^{E}}{A_{t}}\right)^{1 / \rho}
$$

The optimal investment $Z_{t}^{E}$ is such that the marginal benefit and marginal cost of investment are equal:

$$
\eta^{E}\left(1-\rho^{E}\right)\left(\frac{Z_{t}^{E}}{A_{t}}\right)^{-\rho^{E}} \frac{1}{A_{t}} E_{t}\left[\Lambda_{t, t+1} V_{t+1}(1,0)\right]=1
$$

\footnotetext{
${ }^{8}$ This investment is measured in units of the tradable final good.
} 


\subsubsection{Productivity Growth and The Extensive Margins of Trade}

We can now characterize how firm dynamics translate into aggregate productivity growth and into the extensive margins of exports and imports. We denote the share of domestic lines by $\theta_{t}^{D}$, and the share of export lines by $\theta_{t}^{X}$. The share of imported product lines is then $1-\theta_{t}^{D}-\theta_{t}^{X}$. The rate at which product lines are replaced $\left(d_{t}\right)$ is the sum of the probability that a product line is replaced due to domestic entry, domestic innovation, or foreign innovation:

$$
d_{t}=\left(\theta_{t-1}^{D}+\theta_{t-1}^{X}\right) i_{t}^{D}+e_{t}+i^{F}
$$

In this expression, the probability that a product line is replaced due to domestic innovation is equal to the probability a domestic innovation by an incumbernt firm is successful $\left(i_{t}^{D}\right)$ times the share of domestically-owned product lines (which is the sum of domestic and export lines). The law of motion for the share of domestic lines is:

$$
\theta_{t}^{D}=\theta_{t-1}^{D}+\left(1-\theta_{t-1}^{D}\right)\left(e_{t}+\left(\theta_{t-1}^{D}+\theta_{t-1}^{X}\right) i_{t}^{D}\right)-\theta_{t-1}^{D}\left(\left(1-d_{t}\right) i_{t}^{X}+i^{F}\right)
$$

This share increases due to entry by domestic firms and due to domestic innovation by incumbent firms. It decreases due to exporting innovation and foreign innovation.

The law of motion for the share of exporting lines $\theta_{t}^{X}$ is:

$$
\theta_{t}^{X}=\theta_{t-1}^{X}+\theta_{t-1}^{D}\left(1-d_{t}\right) i_{t}^{X}-\theta_{t-1}^{X}\left(e_{t}+\left(\theta_{t-1}^{D}+\theta_{t-1}^{X}\right) i_{t}^{D}+i^{F}\right)
$$

It increases due to export innovations and decreases due to domestic entry, domestic innovation, and foreign innovation. The share of foreign lines is consequently $1-\theta_{t}^{D}-\theta_{t}^{X}$. Note that the extensive margin of imports is determined by endogenous changes in the share of foreign product lines. The extensive margin of exports is determined by endogenous changes in the share of exporting lines.

Aggregate production of the tradable final good is:

$$
Y_{t}^{T}=\exp \left[\int_{0}^{1} \ln y_{t}(i) d i\right]=A_{t}\left[\left(\ell_{t}^{D}\right)^{\alpha}\left(h_{t}^{D}\right)^{1-\alpha}\right]^{\theta_{t-1}^{D}}\left[\left(\ell_{t}^{X}\right)^{\alpha}\left(h_{t}^{X}\right)^{1-\alpha}\right]^{\theta_{t-1}^{X}}\left[\frac{1}{1+\xi}\left(\ell_{t}^{M}\right)^{\alpha}\left(h_{t}^{M}\right)^{1-\alpha}\right]^{1-\theta_{t-1}^{D}-\theta_{t-1}^{X}}
$$

where $\ell_{t}^{D}, \ell_{t}^{X}, \ell_{t}^{M}$ are the amounts of the productive asset used by each product line, and $h_{t}^{D}, h_{t}^{X}, h_{t}^{M}$ are the amounts of labor hired by each product line. Note that $\ell_{t}^{M}$ and $h_{t}^{M}$ are factors employed abroad. ${ }^{9}$

\footnotetext{
${ }^{9}$ Expressions for these variables are left to the appendix.
} 
The average productivity of intermediate firms $\left(A_{t}\right)$ is:

$$
A_{t}=\exp \left[\int_{0}^{1} \ln a_{t}(i) d i\right]
$$

$A_{t}$ grows as productivity of each product line $a_{t}(i)$ improves through domestic firm entry, innovation by incumbent domestic firms, and foreign innovation. ${ }^{10}$ The growth rate of $A_{t}$ is:

$$
\frac{A_{t+1}}{A_{t}}=1+g_{t}=\left(1+\sigma^{D}\right)^{e_{t}+\left(\theta_{t-1}^{D}+\theta_{t-1}^{X}\right) i_{t}^{D}}\left(1+\sigma^{X}\right)^{\theta_{t-1}^{D}\left(1-d_{t}\right) i_{t}^{X}}\left(1+\sigma^{X}\right)^{i^{F}}
$$

Note that the three terms in the right-hand side correspond to the sum of new firm entry and domestic innovations, exporting innovations, and foreign innovations respectively.

\subsection{Nontradable Good}

A representative firm produces a nontradable good using labor $\left(H_{t}^{N}\right)$ according to the following production function:

$$
Y_{t}^{N}=A_{t}\left(H_{t}^{N}\right)^{1-\alpha^{N}}
$$

where $0<1-\alpha^{N}<1$ is the labor share. We assume that total factor productivity in this sector increases at the same rate as aggregate productivity in the tradable sector. This spillover guarantees that production of tradable and nontradable goods grows at the same rate in the long run. Let $P_{t}^{N}$ denote the price of the nontradable good. Since the law of one price holds for the tradable good, the real exchange rate is determined by the price of the nontradable good. An increase in $P_{t}^{N}$ corresponds to a real appreciation.

\subsection{Households}

The representative household consumes the tradable and the nontradable final goods and supplies labor ellastically. In addition it invests $Z_{t}^{E}$ units of the tradable good in domestic entry. They receive income from their wage $W_{t} L_{t}$, from profits from the tradable and nontradable good producers, and from profits from domestic intermediate good producers. The representative household's optimization problem is then to maximize:

$$
\max _{\left\{C_{t}^{T}, C_{t}^{N}, H_{t}, Z_{t}^{E}\right\}_{t=0}^{\infty}} E_{0} \sum_{t=0}^{\infty}\left[\ln \left(C_{t}-A_{t} \frac{\left(H_{t}\right)^{\omega}}{\omega}\right)\right]
$$

with

\footnotetext{
${ }^{10}$ Note that $A_{t}$ is not necessarily the productivity level of this economy, because $A_{t}$ includes prouctivity of foreign firms. But the long-run growth rate of this economy is determined by growth in $A_{t}$.
} 


$$
C_{t}=\left[(\gamma)^{1 / \varepsilon}\left(C_{t}^{T}\right)^{\frac{\varepsilon-1}{\varepsilon}}+(1-\gamma)^{1 / \varepsilon}\left(C_{t}^{N}\right)^{\frac{\varepsilon-1}{\varepsilon}}\right]^{\frac{\varepsilon}{\varepsilon-1}}
$$

subject to their budget constraint:

$$
C_{t}^{T}+P_{t}^{N} C_{t}^{N}+Z_{t}^{E}=W_{t} H_{t}+\Pi_{t}^{T}+\Pi_{t}^{N}+\theta_{t-1}^{D}\left(\pi_{t}^{D}-Z_{t}^{D}-Z_{t}^{X}\right)+\theta_{t-1}^{X}\left(\pi_{t}^{X}+\pi_{t}^{*}-Z_{t}^{D}\right)
$$

where $\gamma$ determines the weight of tradable goods in composite consumption $C_{t}$, and $\varepsilon$ is the constant elasticity of substitution between tradable and nontradable consumption. Optimal investment in domestic entry $Z_{t}^{E}$ is determined by equation (22).

Finally, the trade balance is:

$$
\begin{aligned}
T B_{t}= & \underbrace{Y_{t}^{T}-C_{t}^{T}-Z_{t}^{E}-\theta_{t-1}^{D}\left(Z_{t}^{D}+Z_{t}^{X}\right)-\theta_{t-1}^{X} Z_{t}^{D}}_{\text {final tradable output - absorption }} \\
+ & \underbrace{\left(\theta_{t-1}^{D}+\theta_{t-1}^{X}\right) Y_{t}^{*}}_{\text {export of intermediate goods }}-\underbrace{\left(1-\theta_{t-1}^{D}-\theta_{t-1}^{X}\right) \frac{Y_{t}^{T}}{1+\phi \mu_{t} / \lambda_{t}}}_{\text {import of intermediate goods }}
\end{aligned}
$$

The Appendix defines the equilibrium of the economy and the stationarized equilibrium conditions that we use to solve the model numerically.

\section{Quantitative Analysis}

In this section we show that the calibrated model can replicate the key stylized facts of sudden stop episodes discussed in the introduction, and we contrast the predictions of the model with the response of manufacturing firms' product portfolios to the Chilean sudden stop in 1998.

\subsection{Calibration}

The model is calibrated at an annual frequency. There are 17 parameters to be determined in the model. We take conventional values from the literature if available. In addition we use the firm-product level data described in Section 2. Table 3 shows the values of 12 externally-determined parameter values. The discount factor $\beta=0.96$ and the interest rate on foreign bonds $R=1.06$ are standard values for annual models. The weight of tradable goods in consumption $\gamma=0.31$ is set following Bianchi [2011]. The elasticity of substitution between tradable and nontradable goods in consumption, $\varepsilon=0.6$, is in the middle of the range discussed in Mendoza [2005]. The parameter for the labor supply elasticity 
$\omega=1.455$ is set following Mendoza [1991]. Regarding the production parameters, the asset's share in tradable production $\alpha=0.3$ is a standard value, and the labor share in nontradable production 1 $\alpha^{N}=0.75$ is taken from Schmitt-Grohé and Uribe [2016]. The iceberg trade cost $\xi=0.21$ follows the estimation by Anderson and Van Wincoop [2004]. The fraction of the input cost subject to the working capital requirement $\phi$ varies widely depending on how it is estimated. We set its value to 0.6 , which is in the middle of the range in the literature such as Mendoza [2010] and Ates and Saffie [2016]. The coefficient on the borrowing constraint $\kappa$ is set to 0.13 , which is close to 0.2 assumed in Mendoza [2010]. The concavity parameter governing investment $\rho$ is set to 1.5 , which is the middle value in the literature such as Comin and Gertler [2006], Akcigit and Kerr [2018], and their literature review. The foreign innovation rate is set to 0.03 , which is somewhat arbitrarily set to a low value so that the economy grows mainly through domestic innovation.

Table 3: Externally-Determined Parameters

\begin{tabular}{|c|c|c|c|}
\hline \multicolumn{2}{|r|}{ Variable } & Value & Source \\
\hline$\beta$ & Discount factor & 0.96 & Standard \\
\hline$R$ & Foreign bond interest rate & 1.06 & Standard \\
\hline$\gamma$ & Tradable share in consumption & 0.31 & Bianchi $(2011)$ \\
\hline$\varepsilon$ & CES between $\mathrm{T}$ and NT sectors & 0.6 & Middle value in literature \\
\hline$\omega$ & Frisch elasticity $1 /(\omega-1)$ & 1.455 & Mendoza (1991) \\
\hline$\alpha$ & Asset share in tradable sector & 0.3 & Standard \\
\hline $1-\alpha^{N}$ & Labor share in nontradable sector & 0.75 & Schmitt-Grohe \& Uribe (2016) \\
\hline$\xi$ & Iceberg trade cost & 0.21 & Anderson \& van Wincoop (2004) \\
\hline$\phi$ & Fraction of input subject to WK & 0.6 & Ates \& Saffie (2014) \\
\hline$\kappa$ & Coefficient on borrowing constraint & 0.13 & Debt to GDP ratio \\
\hline$\rho$ & Concavity of innovation investment & 1.5 & Middle value in literature \\
\hline$i^{F}$ & Foreign innovation rate & 0.03 & Export innovation rate \\
\hline
\end{tabular}

Six parameters related to firm dynamics and growth, $\eta^{E}, \eta^{D}, \eta^{X}, \sigma^{D}, \sigma^{X}, Y_{t}^{*}$, are jointly determined to match six moments at the balanced growth path of the model with Chilean data in 2001-2011. The six targeted moments are the share of single-good non-exporting firms, the average product sold by non-exporters, the share of single-good exporters, the average GDP growth rate, the relative profit for non-exporters compared to exporters, and the share of exports in the total revenue for exporters. The values of these parameter and the corresponding targeted moments are listed in Table 4. Our calibration is unique in that we target the detailed firm-product level data, which is explained in more detail in the next subsection.

The aggregate shocks to the economy determine the productivity of the final tradable sector $\varepsilon_{t}^{A}$ and the interest rate on the foreign bond $\varepsilon_{t}^{R}$. We take the stochastic process for these shocks from Mendoza 
Table 4: Jointly-Determined Parameters

\begin{tabular}{c|c|c|c|c|c}
\hline \multicolumn{2}{c|}{ Variable } & Value & Target & Model & Data \\
\hline \hline$\eta^{E}$ & Domestic entry coeff. & 1.98 & Share of single-good non-exporters 38.3\% & $39.6 \%$ & $38.3 \%$ \\
\hline$\eta^{D}$ & Domestic innovation coeff. & 4.05 & Average Product non-exporter, 2.07 & 2.01 & 2.075 \\
\hline$\eta^{X}$ & Export innovation coeff. & 1.42 & Share of single-good exporters $14.9 \%$ & $15.1 \%$ & $14.9 \%$ \\
\hline$\sigma^{D}$ & Domestic innovation size & 0.06 & Average growth rate $2.5 \%$ & $2.5 \%$ & $2.5 \%$ \\
\hline$\sigma^{X}$ & Export innovation size & 0.38 & Relative profits non-exporters to exporters 26.2\% & $26.1 \%$ & $26.2 \%$ \\
\hline$Y^{*}$ & Foreign demand & 0.79 & Export revenue share for exporters 35.9\% & $34.3 \%$ & $35.9 \%$ \\
\hline
\end{tabular}

[2010], in which $\varepsilon_{t}^{A}$ and $\varepsilon_{t}^{R}$ follow a joint discrete Markov process with two realizations for each variable. In particular, $\varepsilon_{t}^{A}$ takes \pm 0.0134 and $\varepsilon_{t}^{R}$ takes \pm 0.0196 with the same autocorrelation 0.59 and the negative correlation -0.67 between $\varepsilon_{t}^{A}$ and $\varepsilon_{t}^{R}$. Finally, the foreign factor prices $R_{t}^{L *}$ and $W_{t}^{*}$ are set equal to the domestic values $R_{t}^{L}$ and $W_{t}$ at the balanced growth path, under the assumption that the domestic foreign economies have a similar productivity level.

\subsection{Validation}

Our calibration is unique in that we target the detailed firm-size distribution in terms of the number of products each firm sells domestically and exports. In the model, each firm is characterized by the number of domestic and exporting lines it owns, $\left(n^{D}, n^{X}\right)$. Let $\delta_{t}\left(n^{D}, n^{X}\right)$ denote the measure of firms that own $n^{D}$ domestic lines and $n^{X}$ exporting lines at period $t$. We derive the firm-size distribution $\delta_{t}\left(n^{D}, n^{X}\right)$ at the balanced growth path of the model using the innovation rates at the balanced growth path. The detailed steps are explained in Appendix A.4. We contrast the distribution obtained from the model from that found in the data of firms' product portfolios of Chilean manufacturing firms described in Section 2. The frequency of exporters and nonexporters selling a single product was targeted in the model calibration, but the rest of the distribution is nontargeted.

Panel 3a in Figure 3 presents the firm-size distribution of the products sold domestically. For example, $40 \%$ of firms are non-exporters and sell a single product, and about $15 \%$ sell two products. Panel $3 \mathrm{~b}$ shows the same distribution for exported products. About $15 \%$ of firms export a single product, $3 \%$ export two products, and so on. These figures show that our model does quite well in replicating the micro-level distribution of the number of products sold domestically and exported. 
Figure 3: Firm-Size Distribution

a) Domestic Lines

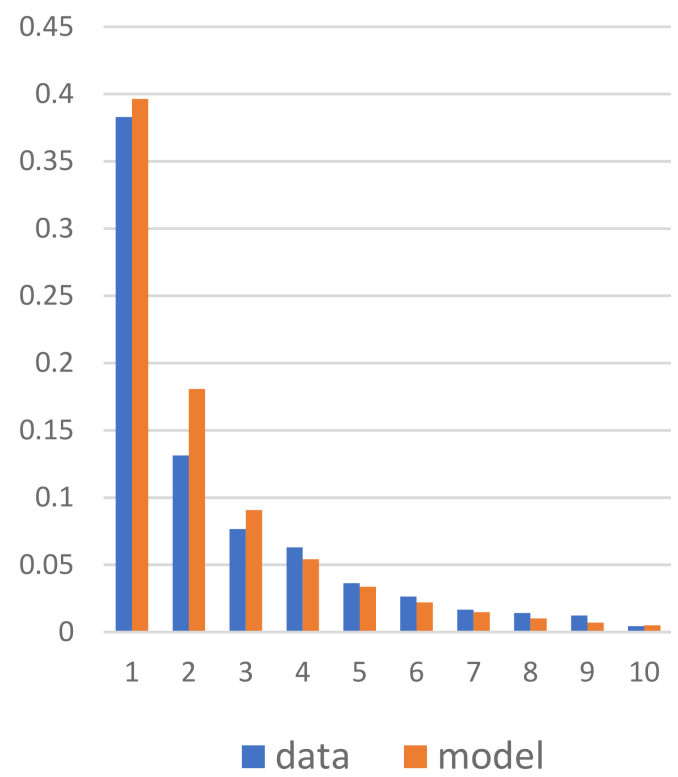

b) Exporting Lines

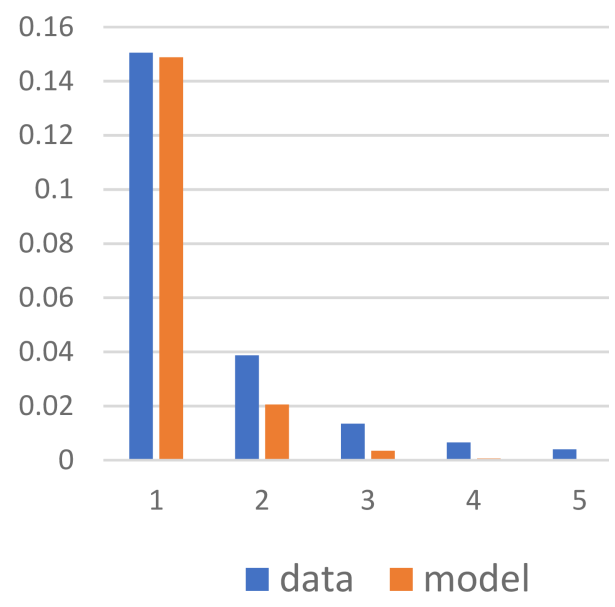

\subsection{Sudden Stop Dynamics}

This section presents sudden stop dynamics in the model. ${ }^{11}$ Following Bianchi and Mendoza [2018], sudden stops are identified as events in which the current account adjusted for its trend is at least two standard deviations above its mean. Under this definition, the unconditional probability of sudden stops in the model is 7.9\%, which is in line with empirical estimations in Eichengreen et al. [2008] and Jeanne and Rancière [2011]. Figure 4 plots the average dynamics of key macroeconomic variables before and after sudden stops events. Panels $4 \mathrm{a}, 4 \mathrm{~b}$ and $4 \mathrm{c}$ show the path of real GDP, consumption, and the asset price in log deviations from their linear trends. ${ }^{12}$ On average, GDP declines by $5 \%$, consumption falls by $3.5 \%$, and the asset price drops by $8 \%$ following a sudden stop. The sharp fall in the asset price indicates that the borrowing limit substantially tightens during sudden stops, and an amplification effect sets in motion as in Mendoza [2010] and Bianchi and Mendoza [2018]. The net foreign asset-toGDP ratio in the left panel of the bottom row has a sharp spike, which indicates a sudden reversal of capital inflows.

Panel 4e illustrates the average path of productivity shocks and interest rate shocks, which cause the sudden stop. Before a sudden stop occurs, productivity is high and the interest rate is low, implying that

\footnotetext{
${ }^{11}$ Details on the simulation of the model are included in the Appendix.

${ }^{12} \mathrm{~A}$ linear trend is constructed by taking the log of 20-period series around each sudden stop (10 periods before and after sudden stop respectively) and taking a linear trend of this log series.
} 
a) GDP

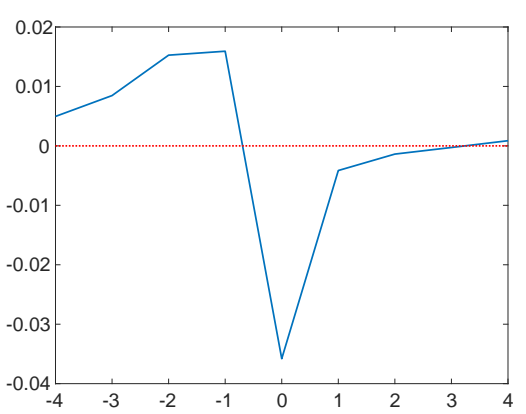

b) Consumption

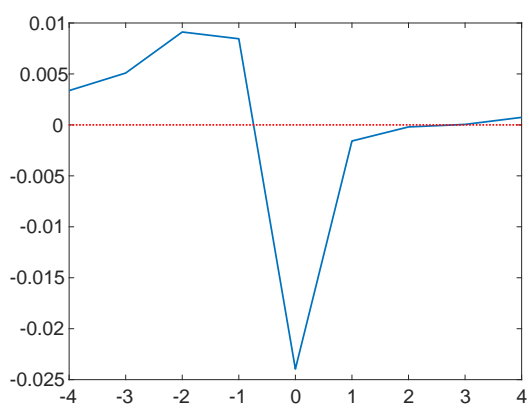

c) Asset Price

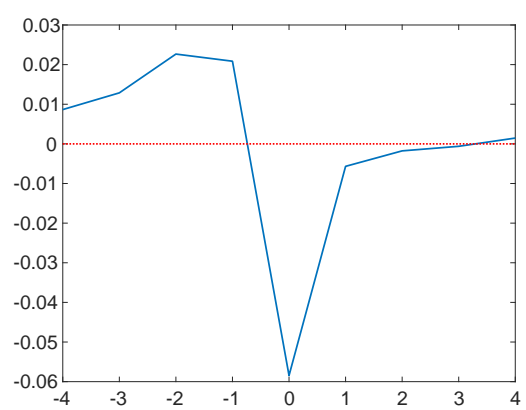

d) Net Foreign Assets / GDP

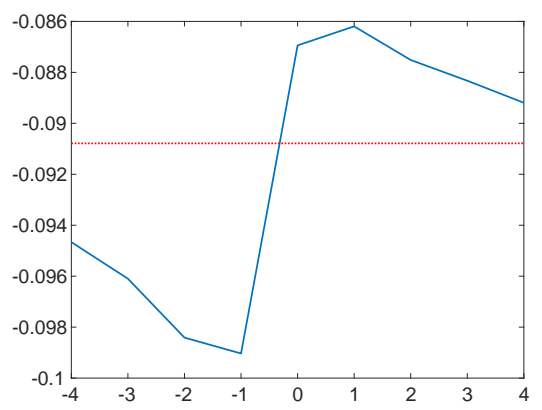

e) TFP and interest rate shock

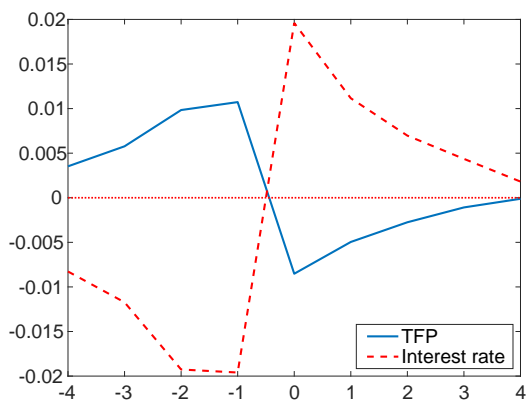

NoтE: This figure shows the path of real GDP, aggregate consumption. the asset price, the ratio of net foreign assets to GDP, the productivity shock, and the interest rate shock around sudden stop episodes.

the country is facing favorable shocks. During this period, the borrowing from abroad increases and the bond holdings-to-GDP ratio is below its mean. When these favorable shocks reverse to bad shocks of low productivity and a high interest rate, the asset price declines and forces the borrowing constraint to bind. Households are then forced to cut consumption, which reduces the asset price further, and the amplification mechanism is set in motion. These developments of exogenous shocks and the subsequent endogenous dynamics are all consistent with Mendoza [2010].

We now examine trade and growth dynamics, which are the novel features of our model. Figure 5 plots the average dynamics of the key variables around sudden stop epsidoes.

Panels $5 \mathrm{c}$ and $5 \mathrm{~d}$ show the dynamics of imports and exports of intermediate goods. We observe that imports fall by much more than exports and stay below the trend persistently, while exports are almost unaffected. A decline in imports occurs because the final tradable producer in this country is constrained by the borrowing limit and is forced to reduce its demand for intermediate goods. In contrast, foreign demand is not affected by the sudden stop in the domestic economy, so exports are unaffected. This stark contrast in import and export dynamics during crises is at least qualitatively consistent with 
Figure 5: Sudden Stops Dynamics: Trade and Growth

a) Innovation Rate

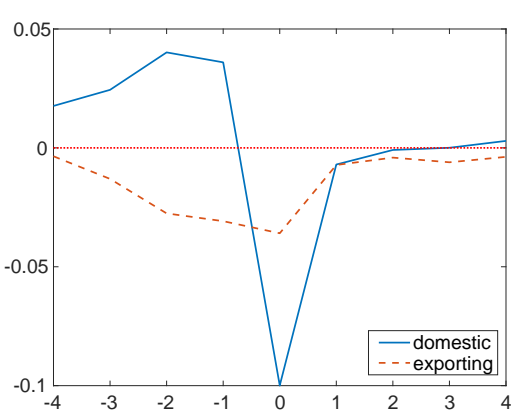

b) Productivity Index $A_{t}$

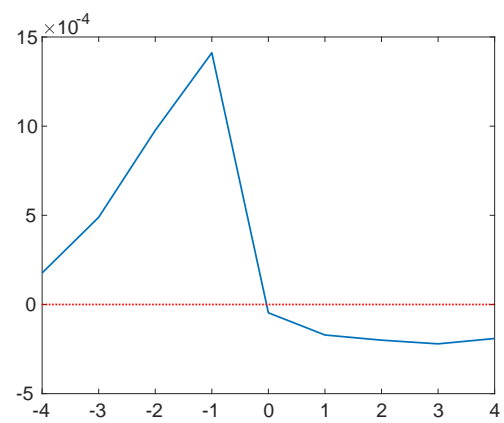

c) Exports of Intermediates

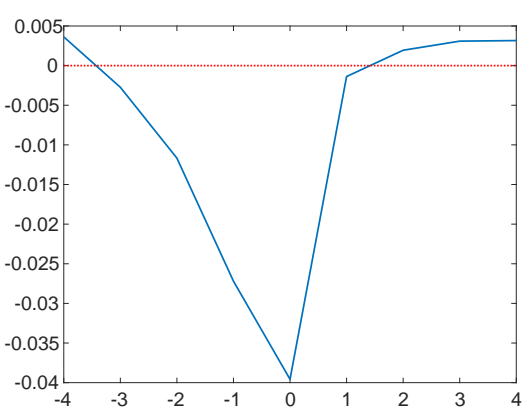

d) Imports of Intermediates

e) Trade Balance / GDP
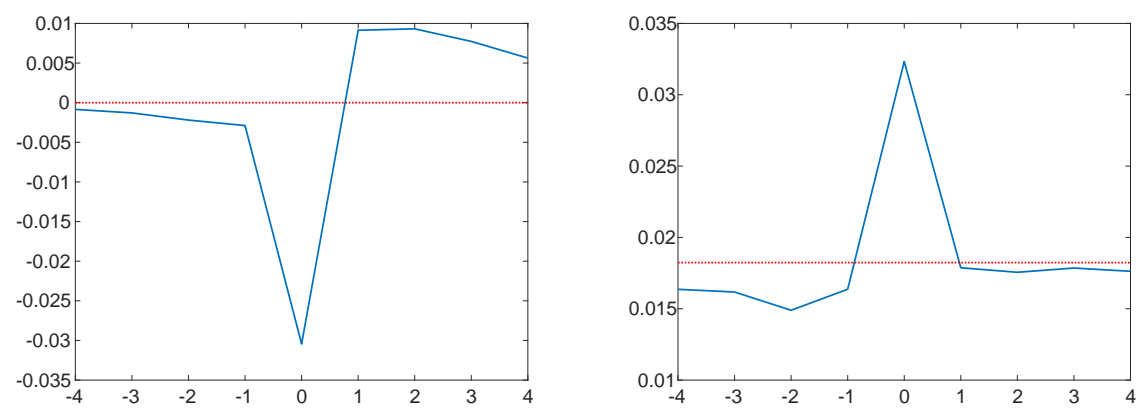

Note: This figure shows the path of the domestic and export innovation rates, the productivity index $\left(A_{t}\right)$, exports and imports of intermediate goods, and the trade balance to GDP ratio around sudden stop episodes.

the empirical facts documented and Alessandria et al. [2014]. Panel 5e shows that the trade balance-toGDP ratio improves during sudden stops, which is also in line with a empirical fact [Mendoza, 2010]. Panels 5a shows firms' innovation rates. In a sudden stop, the rate of domestic innovation falls by $13 \%$ and the rate of export innovation barely diminishes by $0.05 \%$. As a result, growth of the productivity index $A_{t}$ declines sharply. This has a persistent effect on the economy. This long-lasting negative impact is consistent with empirical findings by Cerra and Saxena [2008] and Blanchard et al. [2015].

We analyze in Figure 6 how the extensive margins of trade react to sudden stops. Panels $6 \mathrm{a}$ and $6 \mathrm{~b}$ show a sharp real depreciation as reported in Mendoza [2005] - the real exchange rate and the domestic wage fall by $5 \%$ and $4.5 \%$. This results in a decline in the relative marginal cost of production for domestic firms compared to foreign firms. Panel $6 \mathrm{c}$ shows an increase in the relative productivity of the foreign economy compared to the domestic economy, which implies a larger foreign demand for exports. Due to the decline in the relative marginal cost and increase in relative foreign demand, export profits increase by $13 \%$ above trend as seen in Panel 6d. In contrast, domestic profits do not vary much. This generates a large gap between the expected future stream of domestic and export profits, which 
a) Real Exchange Rate

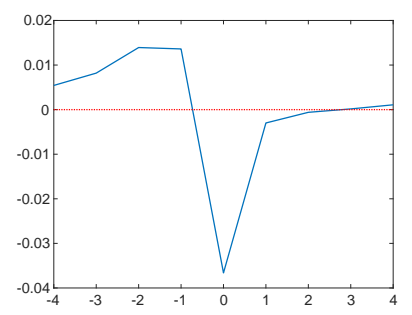

d) Profits in Domestic and Export Product Lines

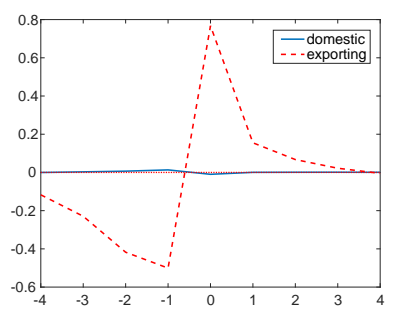

b) Wage

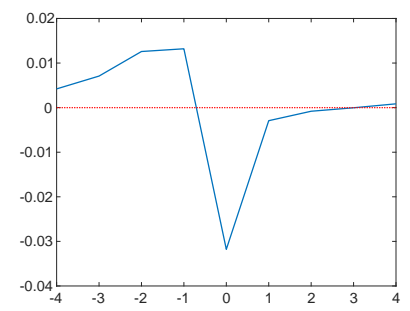

e) Share of Domestic Lines

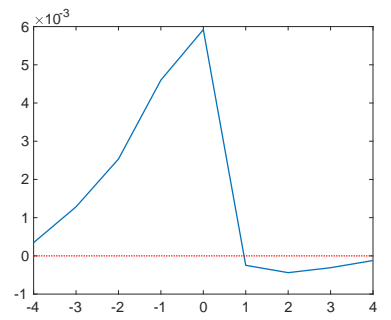

c) Relative Marginal Cost Domestic / Foreign

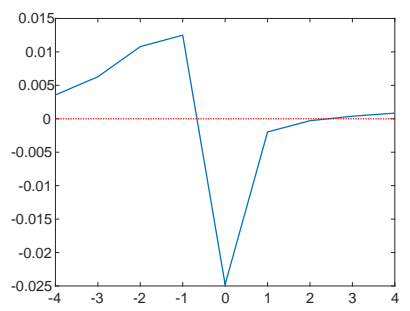

f) Share of Export Lines

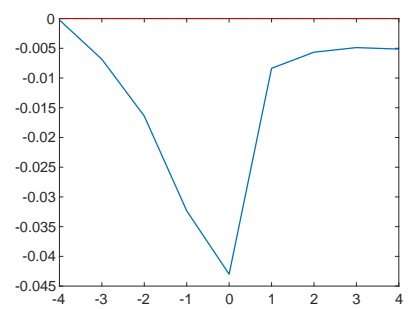

Note: This figure shows the path of the real exchange rate, the wage, the ratio of domestic to foreign marginal cost, domestic and export profits, the share of export product lines, and the share of domestic product lines around sudden stop episodes.

in turn affects firms' investment decisions. As we discussed earlier, export and especially domestic innovation rates decline. These endogenous firm-level responses shape the evolution of the extensive trade margins. Panel $6 \mathrm{f}$ shows a gradual increase in the share of export lines following the sudden stop. This is a consequence of the increased investment in export innovation compared to domestic innovation. This gradual expansion of the extensive margin of exports is in line with the empirical fact reported in Alessandria et al. [2014]. Panel 6e shows a decline in the share of domestic product lines.

\subsection{The Dynamics of Firm Product Portfolios: Evidence from Chile’s 1998 Sudden Stop}

In 1998 Chile faced a severe sudden stop common to several other emerging markets as a consequence of the Russian default in the same year and the Asian crises. This event was both unanticipated and exogenous to the Chilean economy, which had few direct ties with the countries in which this crisis originated. The sudden stop sharply decreased GDP growth and capital inflows. Calvo and Talvi [2005] discuss this episode in detail for Chile and other large Latin American economies which faced similar sudden stops at the time.

The model has clear predictions regarding the dynamics of firms' product portfolios during sudden stops. In terms of the extensive margin, it predicts that the rate at which firms add products into the 
domestic market falls relative to the export market. In addition, it predicts that revenue from domestic products falls relative to revenue obtained from export products. Our goal in this section is to contrast this predictions with the behavior of Chilean manufacturing firms during this episode. We use the same dataset described in Section 2, in which we observe the universe of products produced by each manufacturing firm. We focus on a panel of firms between 1996 and 1999. We observe the revenue of each product sold by each firm. The data distinguishes between revenue from domestic or export sales for each individual product.

In Section 2 we documented the frequency with which firms introduce new products to the domestic market, export products previously sold domestically, drop products from the domestic market, and drop export products subsequently selling them only domestically. Here we show how the probability that each of these events take place evolves over time before and during the Chilean sudden stop episode. During the sudden stop, the probability that firms introduce domestic products falls relative to the years prior to the sudden stop. The probability of exporting products previously limited to the domestic market in comparison falls to a much lesser extent, consistent with the predictions of the model. The probability that a firm drops a domestic product rises during the sudden stop, while the probability of exported products becoming restricted to the domestic market remains roughly flat.

To establish these patterns, we estimate the following regression in which $Y_{f t}$ is a dummy variable taking a value of one if a transition takes place between years $t-1$ and $t$ and zero otherwise. This regression includes firm fixed effects and dummy variables for each year (with the first year - 1997 being the omitted category).

$$
Y_{f t}=\phi_{f}+\beta_{1} \cdot 1[\text { year }=1998]_{t}+\beta_{2} \cdot 1[\text { year }=1999]_{t}+\epsilon_{f t}
$$

The results are shown in Table 5. Column 1 indicates that the probability that a firm introduces one or more new domestic products between 1998 and 1999 is 0.267 percentage points lower (0.25 standard deviations lower) than between 1996 and 1997. Column 2 shows that the probability that a firm introduces one or more new exported products previously sold domestically between 1998 and 1999 is 0.025 percentage points lower (0.09 standard deviations lower) than between 1996 and 1997. Column 3 shows that the probability that a firm drops one or more domestic products between 1998 and 1999 is 0.498 percentage points higher (0.34 standard deviations higher) than between 1996 and 1997. Finally column 4 suggests that the probability that a firm drops one or more exported products (subsequently selling them domestically) between 1998 and 1999 is practically identical (0.01 percentage points or 0.03 standard deviations lower) than between 1996 and 1997.

Next we show that revenue from domestic products fell relative to revenue from exported products 
during the sudden stop episode. To this end we estimate the following regression in which each observation is a firm-product-year combination. The dependent variable is the (log) revenue obtained by firm $f$ from selling product $p$ in time $t$ and destination $d$ (either the domestic or export market). We include firm, product and destination fixed effects. In addition we include year dummy variables for 1997, 1998, and 1999 (the omitted category is 1996) and the interaction between these year dummies

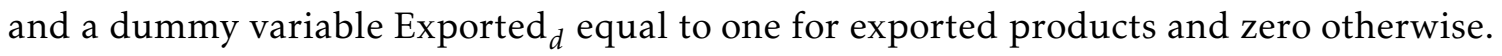

$$
\begin{aligned}
& \log \left(\text { Revenue }_{f p d t}\right)= \phi_{f}+\delta_{p}+v_{d}+ \\
& \beta_{1} \cdot 1[\text { year }=1997]_{t}+\beta_{2} \cdot 1[\text { year }=1998]_{t}+\beta_{3} \cdot 1[\text { year }=1999]_{t}+ \\
& \beta_{3} \cdot 1[\text { year }=1997]_{t} \cdot \text { Exported }_{d}+\beta_{4} \cdot 1[\text { year }=1998]_{t} \cdot \text { Exported }_{d^{+}} \\
& \beta_{4} \cdot 1[\text { year }=1999]_{t} \cdot \text { Exported }_{d}+\epsilon_{f p d t}
\end{aligned}
$$

The results are shown in Table 6. According to column 1, firms' revenue from exported products is $12.3 \mathrm{log}$ points higher relative to domestic products in 1997 compared to 1996, $12.6 \mathrm{log}$ points higher in 1998 relative to 1996, and practically identical in 1999 relative to 1996 . Column 2 replaces the firm and product fixed effects for firm-product fixed effects and shows very similar results, in which revenue from exported products increases relative to revenue from domestic products in 1997 and 1998 relative to 1996, and not statistically different from the 1996 difference in 1999.

Table 5: Probability of Adding or Dropping Products during the Sudden Stop

\begin{tabular}{lcccc}
\hline \hline & $(1)$ & $(2)$ & $(3)$ & $(4)$ \\
\hline & & & & \\
$1[\text { year }=1998]_{t}$ & $-0.138^{* * *}$ & $-0.020^{* * *}$ & $0.226^{* * *}$ & $0.014^{* *}$ \\
& $(0.018)$ & $(0.005)$ & $(0.023)$ & $(0.006)$ \\
1 year $=1999]_{t}$ & $-0.267^{* * *}$ & $-0.025^{* * *}$ & $0.498^{* * *}$ & -0.010 \\
& $(0.019)$ & $(0.006)$ & $(0.025)$ & $(0.006)$ \\
\hline Observations & 15523 & 15523 & 15523 & 15523 \\
\hline \hline
\end{tabular}

Note: This table reports the results of the estimation of equation 30 . The transitions in each column are (1) a firm introduces to the domestic market a product not sold previously, (2) a firm introduces to the export market a product previously sold domestically, (3) a firm withdraws a product from the domestic market, subsequently not selling it, (4) a firm withdraws a product from the export market, subsequently selling it domestically. ${ }^{* *},{ }^{* *}$, and ${ }^{\star}$ denote statistical significance at a 1, 5 and 10 percent confidence level. 
Table 6: Revenue from Domestic and Exported Products during the Sudden Stop

\begin{tabular}{lcc}
\hline \hline & $(1)$ & $(2)$ \\
\hline & & \\
$1[\text { year }=1997]_{t} \cdot$ Exported $_{f p t}$ & $0.123^{* *}$ & $0.107^{* *}$ \\
& $(0.052)$ & $(0.045)$ \\
$1[\text { year }=1998]_{t} \cdot$ Exported $_{f p t}$ & $0.126^{* *}$ & $0.099^{* *}$ \\
& $(0.054)$ & $(0.047)$ \\
$1[\text { year }=1999]_{t} \cdot$ Exported $_{f p t}$ & -0.002 & -0.051 \\
& $(0.061)$ & $(0.053)$ \\
& & \\
Firm Fixed Effects & Yes & No \\
Product Fixed Effects & Yes & No \\
Firm-Product Fixed Effects & No & Yes \\
\hline Observations & 56587 & 52439 \\
\hline \hline
\end{tabular}

Note: This table reports the results of the estimation of equation 31. Column 1 corresponds to the case with firm and product fixed effects. Column 2 corresponds to the case with firm-product fixed effects. $* * *, * *$ and ${ }^{*}$ denote statistical significance at a 1,5 and 10 percent confidence level.

\section{Conclusions}

Sudden stops are characterized by sharp devaluations, trade balance reversals, a decline in output explained by lower productivity, and a slow recoveries in which trade dynamics play a key role. To account for these features, we build a model of productivity and trade dynamics in sudden stops. For this purpose we develop an open economy version of a Klette and Kortum [2004] model of endogenous growth. We embed this framework in an endogenous sudden stop model due to an occassionally binding collateral constraint. We calibrate the model using unique firm-product level data from an emerging economy. We show that the model replicates the key stylized facts of sudden stop episodes mentioned above. In addition, we find that the predictions of the model are consistent with the dynamics of firms' product portfolios during the Chilean sudden stop of 1998.

\section{References}

D. Acemoglu, U. Akcigit, H. Alp, N. Bloom, and W. Kerr. Innovation, reallocation, and growth. American Economic Review, 108(11):3450-91, 2018.

U. Akcigit and W. R. Kerr. Growth through heterogeneous innovations. Journal of Political Economy, 126(4):1374-1443, 2018.

U. Akcigit, S. T. Ates, and G. Impullitti. Innovation and trade policy in a globalized world. Working Paper, 2018. 
Ö. Akıncı and R. Chahrour. Good news is bad news: leverage cycles and sudden stops. Journal of International Economics, 114:362-375, 2018.

G. Alessandria, S. Pratap, V. Yue, et al. Export dynamics in large devaluations. Working Paper, 2014.

L. Alfaro, A. Cunat, H. Fadinger, and Y. Liu. The real exchange rate, innovation and productivity: Regional heterogeneity, asymmetries and hysteresis. Harvard Business School BGIE Unit Working Paper, (18-044), 2018.

J. E. Anderson and E. Van Wincoop. Trade costs. Journal of Economic literature, 42(3):691-751, 2004.

S. Ates and F. Saffie. Fewer but better: Sudden stops, firm entry, and financial selection. Working Paper, 2016.

A. B. Bernard and J. B. Jensen. Exporting and productivity in the usa. Oxford Review of Economic Policy, 20(3):343-357, 2004.

J. Bianchi. Overborrowing and systemic externalities in the business cycle. American Economic Review, 101(7):3400-3426, 2011.

J. Bianchi and E. G. Mendoza. Optimal time-consistent macroprudential policy. Journal of Political Economy, 126(2):588-634, 2018.

O. Blanchard, E. Cerutti, and L. Summers. Inflation and activity-two explorations and their monetary policy implications. Working Paper, 2015.

J. Blaum. Importing, exporting and aggregate productivity in large devaluations. Working Paper, 2017.

N. Bloom, M. Schankerman, and J. Van Reenen. Identifying technology spillovers and product market rivalry. Econometrica, 81(4):1347-1393, 2013.

F. J. Buera and E. Oberfield. The global diffusion of ideas. Working Paper, 2016.

G. A. Calvo and E. Talvi. Sudden stop, financial factors and economic collpase in latin america: learning from argentina and chile. 2005.

V. Cerra and S. C. Saxena. Growth dynamics: the myth of economic recovery. American Economic Review, 98(1):439-57, 2008.

D. Comin and M. Gertler. Medium-term business cycles. American Economic Review, 96(3):523-551, 2006. 
B. Eichengreen, P. Gupta, and A. Mody. Sudden stops and imf-supported programs. In Financial markets volatility and performance in emerging markets, pages 219-266. University Of Chicago Press, 2008.

N. Gornemann. Sovereign default, private investment, and economic growth. Working Paper, 2014.

P. A. Guerron-Quintana and R. Jinnai. Financial frictions, trends, and the great recession. Working Paper, 2018.

O. Jeanne and A. Korinek. Macroprudential regulation versus mopping up after the crash. Working Paper, 2013.

O. Jeanne and R. Rancière. The optimal level of international reserves for emerging market countries: A new formula and some applications. The Economic Journal, 121(555):905-930, 2011.

T. J. Klette and S. Kortum. Innovating firms and aggregate innovation. Journal of political economy, 112 (5):986-1018, 2004.

R. Lentz and D. T. Mortensen. An empirical model of growth through product innovation. Econometrica, 76(6):1317-1373, 2008.

C. Ma. Financial stability, growth and macroprudential policy. Working Paper, 2017.

H. Matsumoto. Reserve accumulation, foreign direct investment, and economic growth. Working Paper, 2018.

E. G. Mendoza. Real business cycles in a small open economy. The American Economic Review, pages 797-818, 1991.

E. G. Mendoza. Real exchange rate volatility and the price of nontradable goods in economies prone to sudden stops. Economia, 2005.

E. G. Mendoza. Sudden stops, financial crises, and leverage. American Economic Review, 100(5): 1941-66, 2010.

L. Navarro. Plant level evidence on product mix changes in chilean manufacturing. The Journal of International Trade E Economic Development, 21(2):165-195, 2012.

P. A. Neumeyer and F. Perri. Business cycles in emerging economies: the role of interest rates. Journal of monetary Economics, 52(2):345-380, 2005.

J. Perla, C. Tonetti, and M. E. Waugh. Equilibrium technology diffusion, trade, and growth. 2015. 
A. Queralto. A model of slow recoveries from financial crises. Working Paper, 2013.

T. Sampson. Dynamic selection: an idea flows theory of entry, trade, and growth. The Quarterly Journal of Economics, 131(1):315-380, 2015.

S. Schmitt-Grohé and M. Uribe. Downward nominal wage rigidity, currency pegs, and involuntary unemployment. Journal of Political Economy, 124(5):1466-1514, 2016.

H. Seoane and E. Yurdagul. On overborrowing: Trend shocks and capital controls. Working Paper, 2017.

M. Uribe and V. Z. Yue. Country spreads and emerging countries: Who drives whom? Journal of international Economics, 69(1):6-36, 2006.

N. Voigtlaender and A. Garcia-Marin. Exporting and plant-level efficiency gains: It's in the measure. Working Paper, 2018. 


\section{A Appendix}

\section{A.1 Equilibrium and Stationarized Equilibrium}

This section defines the equilibrium of the economy and the stationarized equilibrium.

\section{A.1.1 Factor Allocation}

Before defining the equilibrium, we derive the expressions for asset and labor allocations. First we show that the total cost for production $R_{t}^{L} \ell_{t}(i)+W_{t} h_{t}(i)$ is equal to production $y_{t}(i)$ times the marginal cost. The latter can be written as:

$$
y_{t}(i) \times M C_{t}(i)=a_{t}(i)\left(\ell_{t}(i)\right)^{\alpha}\left(h_{t}(i)\right)^{1-\alpha} \times \frac{1}{a_{t}(i)} \bar{\alpha}\left(R_{t}^{L}\right)^{\alpha}\left(W_{t}\right)^{1-\alpha}=\bar{\alpha}\left(R_{t}^{L} \ell_{t}(i)\right)^{\alpha}\left(W_{t} h_{t}(i)\right)^{1-\alpha}
$$

Using the cost minimization condition $R_{t}^{L} \ell_{t}(i) / W_{t} h_{t}(i)=\alpha /(1-\alpha)$,

$$
y_{t}(i) \times M C_{t}(i)=\frac{1}{\alpha} R_{t}^{L} \ell_{t}(i)=\frac{1}{1-\alpha} W_{t} h_{t}(i)=R_{t}^{L} \ell_{t}(i)+W_{t} h_{t}(i)
$$

Thus production times the marginal cost is equal to the total cost.

Next, profit for a product line can be written as follows:

$$
\pi_{t}(i)=p_{t}(i) y_{t}(i)-\left(R_{t}^{L} \ell_{t}(i)+W_{t} h_{t}(i)\right)=\left(p_{t}(i)-M C_{t}(i)\right) y_{t}(i)
$$

Recall that the optimal price is equal to the marginal cost for the second-best rival. Here we consider only the case in which the second-best rival is a domestic firm, but the case in which the rival is a foreign firm is similar. The rival's marginal cost is $\left(1+\sigma^{s}\right)$ times the marginal cost for the leader, where $s=D, X$ depending on the type of the product line. Therefore,

$$
\pi_{t}(i)=\sigma^{s} M C_{t}(i) y_{t}(i)
$$

Using (32),

$$
\pi_{t}(i)=\sigma^{s} \frac{1}{\alpha} R_{t}^{L} \ell_{t}(i)=\sigma^{s} \frac{1}{1-\alpha} W_{t} h_{t}(i)
$$

In the main text, we derived another expression for a profit in equation (8). Thus we have:

$$
\sigma^{s} \frac{1}{\alpha} R_{t}^{L} \ell_{t}(i)=\sigma^{s} \frac{1}{1-\alpha} W_{t} h_{t}(i)=Y_{t}^{T} \frac{1}{1+\phi \mu_{t} / \lambda_{t}} \frac{\sigma^{s}}{1+\sigma^{s}}
$$

This equation shows that the asset and labor input $\ell_{t}(i)$ and $h_{t}(i)$ are independent of productivity $a_{t}(i)$, 
and depends only on the type of product lines, $s=D, X$. Combining this equation with $s=D$ and $s=X$, we obtain the relative factor input between domestic lines and exporting lines:

$$
\frac{\ell_{t}^{D}}{\ell_{t}^{X}}=\frac{h_{t}^{D}}{h_{t}^{X}}=\frac{1+\sigma^{X}}{1+\sigma^{D}}
$$

\section{A.1.2 Stationarized Equilibrium}

To stationarize the model, we divide the equilibrium conditions by aggregate productivity $A_{t}$. We denote stationarized variables by the lower-case letters, and use $g_{t}$ to denote the productivity growth rate $A_{t+1} / A_{t}$. We also make some arrangements and reduce the number of equations. The following is the complete list of equations to characterize the stationarized equilibrium of the model:

Tradable goods producers

$$
\begin{gathered}
y_{t}^{T}=\exp \left(\varepsilon_{t}^{A}\right) A_{t} \frac{\left(L_{t}^{D}\right)^{\alpha}\left(H_{t}^{D}\right)^{1-\alpha}}{\theta_{t-1}^{D}}\left(\frac{1+\sigma^{D}}{1+\sigma^{X}}\right)^{1-\theta_{t-1}^{D}} \\
\lambda_{t}-\mu_{t}=\beta \exp \left(\varepsilon_{t}^{R}\right) E_{t}\left(\lambda_{t+1}\right) \\
\lambda_{t} q_{t}=\beta E_{t}\left[\lambda_{t+1}\left(q_{t+1}+r_{t+1}^{L}\right)+\mu_{t+1} \kappa q_{t+1}\right] \\
\mu_{t}\left[-b_{t}+\phi y_{t}^{T} \frac{1}{1+\phi \mu_{t} / \lambda_{t}}-\kappa q_{t}\right]=0
\end{gathered}
$$

Intermediate goods producing firms

$$
\begin{gathered}
R_{t}^{L}=\frac{1}{1+\sigma^{D}} \alpha y_{t}^{T} \frac{\theta_{t-1}^{D}}{L_{t}^{D}} \frac{1}{1+\phi \mu_{t} / \lambda_{t}} \\
W_{t}=\frac{1}{1+\sigma^{D}}(1-\alpha) y_{t}^{T} \frac{\theta_{t-1}^{D}}{H_{t}^{D}} \frac{1}{1+\phi \mu_{t} / \lambda_{t}} \\
L_{t}^{X}=L_{t}^{D} \frac{\theta_{t-1}^{X}}{\theta_{t-1}^{D}} \frac{1+\sigma^{D}}{1+\sigma^{X}} \\
H_{t}^{X}=H_{t}^{D} \frac{\theta_{t-1}^{X}}{\theta_{t-1}^{D}} \frac{1+\sigma^{D}}{1+\sigma^{X}} \\
\pi_{t}^{D}=\frac{\sigma_{t}^{D}}{1+\sigma_{t}^{D}} y_{t}^{T} \frac{1}{1+\phi \mu_{t} / \lambda_{t}} \\
\pi_{t}^{X}=\frac{\sigma_{t}^{X}}{1+\sigma_{t}^{X}} y_{t}^{T} \frac{1}{1+\phi \mu_{t} / \lambda_{t}} \\
\pi_{t}^{*}=y_{t}^{*}-\frac{1+\xi}{1+\sigma^{X}} \frac{1}{\omega^{*}}\left(r_{t}^{L}\right)^{\alpha}\left(w_{t}\right)^{1-\alpha}
\end{gathered}
$$




$$
\begin{gathered}
1=\frac{1+\sigma^{X}}{1+\xi} \bar{\alpha} \omega^{*} \frac{1}{\theta_{t-1}^{X}}\left(L_{t}^{*}\right)^{\alpha}\left(H_{t}^{*}\right)^{1-\alpha} \\
v_{t}(1,0)=\pi_{t}^{D}-z_{t}^{D}-z_{t}^{X}+\left[i_{t}^{D}+\left(1-d_{t}\right)\left(1-i_{t}^{X}\right)\right] E_{t}\left(\Lambda_{t, t+1} v_{t+1}(1,0)\right)+\left(1-d_{t}\right) i_{t}^{X} E_{t}\left(\Lambda_{t, t+1} v_{t+1}(0,1)\right) \\
v_{t}(0,1)=\pi_{t}^{X}+\pi_{t}^{*}-z_{t}^{D}+i_{t}^{D} E_{t}\left(\Lambda_{t, t+1} v_{t+1}(1,0)\right)+\left(1-d_{t}\right) E_{t}\left(\Lambda_{t, t+1} v_{t+1}(0,1)\right) \\
i_{t}^{D}=\eta^{D}\left(z_{t}^{D}\right)^{1 / \rho} \\
\eta^{D} \frac{1}{\rho}\left(z_{t}^{D}\right)^{1 / \rho-1} E_{t}\left(\Lambda_{t, t+1} v_{t+1}(1,0)\right)=1 \\
i_{t}^{X}=\eta^{X}\left(z_{t}^{X}\right)^{1 / \rho} \\
\left(1-d_{t}\right) \eta^{X} \frac{1}{\rho}\left(z_{t}^{X}\right)^{1 / \rho-1}\left(E_{t}\left(\Lambda_{t, t+1} v_{t+1}(0,1)\right)-E_{t}\left(\Lambda_{t, t+1} v_{t+1}(1,0)\right)\right)=1
\end{gathered}
$$

\section{Aggregate variables}

$$
\begin{gathered}
d_{t}=\left(\theta_{t-1}^{D}+\theta_{t-1}^{X}\right) i_{t}^{D}+e_{t}+i^{F} \\
\theta_{t}^{D}=\theta_{t-1}^{D}+\left(1-\theta_{t-1}^{D}\right)\left(e_{t}+\left(\theta_{t-1}^{D}+\theta_{t-1}^{X}\right) i_{t}^{D}\right)-\theta_{t-1}^{D}\left(\left(1-d_{t}\right) i_{t}^{X}+i^{F}\right) \\
\theta_{t}^{X}=\theta_{t-1}^{X}+\theta_{t-1}^{D}\left(1-d_{t}\right) i_{t}^{X}-\theta_{t-1}^{X}\left(e_{t}+\left(\theta_{t-1}^{D}+\theta_{t-1}^{X}\right) i_{t}^{D}+i^{F}\right) \\
1+g_{t}=\left(1+\sigma^{D}\right)^{e_{t}+\left(\theta_{t-1}^{D}+\theta_{t-1}^{X}\right) i_{t}^{D}}\left(1+\sigma^{X}\right)^{\theta_{t-1}^{D}\left(1-d_{t}\right) i_{t}^{X}}\left(1+\sigma^{X}\right)^{i^{F}} \\
a_{t}^{*}=\frac{1+\bar{g}}{1+g_{t}} a_{t-1}^{*}
\end{gathered}
$$

\section{Non-tradable goods producer}

$$
\begin{gathered}
y_{t}^{N}=\left(H_{t}^{N}\right)^{1-\alpha^{N}} \\
w_{t}=P_{t}^{N}\left(1-\alpha^{N}\right)\left(H_{t}^{N}\right)^{-\alpha^{N}}
\end{gathered}
$$

\section{Households}

$$
\begin{gathered}
c_{t}^{T}+z_{t}^{E}=y_{t}^{T}-\theta_{t-1}^{D}\left(Z_{t}^{D}+Z_{t}^{X}\right)-\theta_{t-1}^{X} Z_{t}^{D}+\left(\theta_{t-1}^{D}+\theta_{t-1}^{X}\right) Y_{t}^{*}-\left(1-\theta_{t-1}^{D}-\theta_{t-1}^{X}\right) \frac{Y_{t}^{T}}{1+\phi \mu_{t} / \lambda_{t}}-b_{t}+\exp \left(\varepsilon_{t-1}^{R}\right) R \frac{b_{t-1}}{1+g_{t-1}} \\
\frac{c_{t}^{T}}{y_{t}^{N}}=\frac{\gamma}{1-\gamma}\left(P_{t}^{N}\right)^{\varepsilon} \\
\left(H_{t}\right)^{\omega-1}=w_{t}\left(\gamma \frac{c_{t}}{c_{t}^{T}}\right)^{\frac{1}{\varepsilon}} \\
\lambda_{t}=\frac{1}{c_{t}-\left(H_{t}\right)^{\omega} / \omega}\left(\gamma \frac{c_{t}}{c_{t}^{T}}\right)^{1 / \varepsilon} \\
e_{t}^{D}=\eta^{E}\left(z_{t}^{E}\right)^{1 / \rho}
\end{gathered}
$$




$$
\eta^{E} \frac{1}{\rho}\left(z_{t}^{E}\right)^{1 / \rho-1} E_{t}\left(\Lambda_{t, t+1} v_{t+1}(1,0)\right)=1
$$

Market clearing

$$
\begin{gathered}
H_{t}=H_{t}^{D}+H_{t}^{X}+H_{t}^{*}+H_{t}^{N} \\
1=L_{t}^{D}+L_{t}^{X}+L_{t}^{*}
\end{gathered}
$$

\section{A.2 Numerical Solution}

In this section we sketch the numerical solution method. The solution method is a version of the policy function iteration, modified to deal with the occasionally binding constraint. Below is the procedure to obtain the numerical solution.

1. We set the equally-spaced grid points for the endogenous state variables, foreign debt $\exp \left(\varepsilon_{t}^{R}\right) R b_{t-1} /(1+$ $\left.g_{t-1}\right)$, share of domestic product lines $\theta_{t-1}^{D}$, share of exporting product lines $\theta_{t-1}^{X}$, relative productivity of foreign countries over the domestic country $a_{t}^{*}=A_{t}^{*} / A_{t}$. There are also 2 states for stochastic shocks $\varepsilon_{t}^{A}$ and $\varepsilon_{t}^{R}$ respectively.

2. For each grid point, we set the initial guess for five variables: $c_{t}^{T}, E_{t}\left(\Lambda_{t, t+1} v_{t+1}(1,0)\right), E_{t}\left(\Lambda_{t, t+1} v_{t+1}(0,1)\right)$, $L_{t}^{D}, q_{t}$.

3. For each grid point, we do the following:

(a) We leave the five variables we have made guess for as unknown variables, and express all the other endogenous variables in terms of the state variables and five unknowns. In this process we first assume that the borrowing constraint is not binding and proceed. Later we check if the constraint is satisfied. If it is not satisfied, we recalculate all the variables using the binding borrowing constraint. The other endogenous variables, which include next-period state variables, are now functions of the five variables.

(b) Using multi-dimensional linear interpolation over the next-period state variables and the guess for the five variables $\left(c_{t}^{T}, E_{t}\left(\Lambda_{t, t+1} v_{t+1}(1,0)\right), E_{t}\left(\Lambda_{t, t+1} v_{t+1}(0,1)\right), L_{t}^{D}, q_{t}\right)$, we compute all the endogenous variables next period. we then calculate all the forward-looking expectation terms, such as the right-hand side of the Euler equations and the value functions.

(c) All the equilibrium conditions are now the functions of the initial five unknowns. There are five equations we did not use in step (a), thus five equations in total. We solve for the five unknowns using non-linear solver. 
4. We check the gap between the guess and the newly-obtained values for the five variables. If they are close enough, we stop. If not, we update the guess by the newly-obtained values, and go back to step 3. Repeat this process until the gap becomes sufficiently small.

We check the accuracy of the numerical solution using the Euler equation error. We simulate the model for 100,000 periods with stochastic shocks and compute the Euler equation error for each period. Figure 7 plots the distribution of the Euler equation errors obtained in this way. The average error is smaller than -4 and the maximum error is smaller than -2 , which is reasonably small compared to the literature.

Figure 7: Distribution of Euler Equation Errors

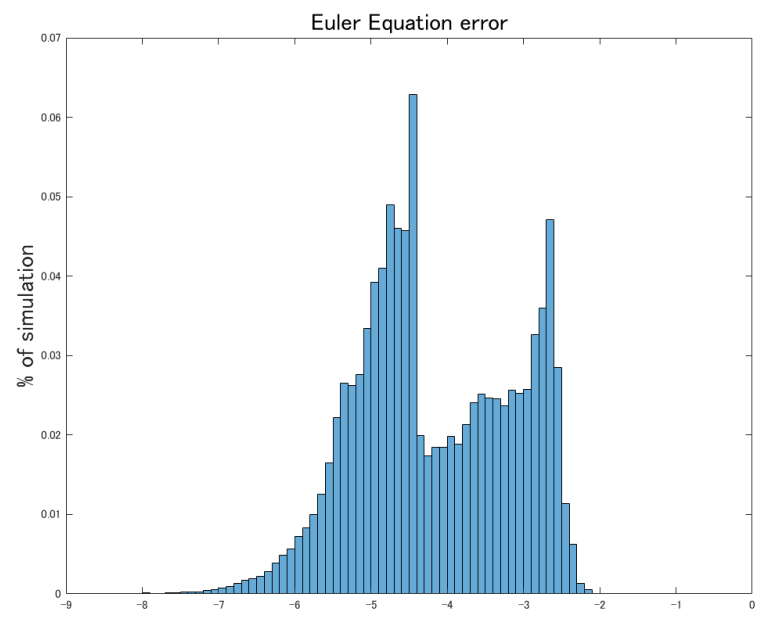

\section{A.3 Proof of Linear Relations in Value Functions}

This section shows the detailed procedure of the guess-and-verify method to prove the linear relation in value functions for intermediate producing firms. We guess the linear relation $V_{t}\left(n^{D}, n^{X}\right)=n^{D} V_{t}(1,0)+$ $n^{X} V_{t}(0,1)$ and prove it. We first work on the value of a firm with a single domestic product line:

$$
\begin{aligned}
V_{t}(1,0)= & \max _{Z_{t}^{D}, Z_{t}^{X}}\left\{\pi_{t}^{D}-Z_{t}^{D}-Z_{t}^{X}\right. \\
& \left.+\left[\sum_{i=0}^{1} P\left(i, 1, i_{t}^{D}\right)\left\{\sum_{j=0}^{1} P\left(j, 1, d_{t}\right)\left(\sum_{k=0}^{1-j} P\left(k, 1-j, i_{t}^{X}\right) E_{t}\left[\Lambda_{t, t+1} V_{t+1}(1+i-j-k, k)\right]\right)\right\}\right]\right\}
\end{aligned}
$$


Using the linear relation, the summations in the second line can be written as follows:

$$
\begin{aligned}
& \sum_{i=0}^{1} P\left(i, 1, i_{t}^{D}\right)\left\{\sum_{j=0}^{1} P\left(j, 1, d_{t}\right)\left(\sum_{k=0}^{1-j} P\left(k, 1-j, i_{t}^{X}\right) E_{t}\left[\Lambda_{t, t+1} V_{t+1}(1+i-j-k, k)\right]\right\}\right) \\
= & \sum_{i=0}^{1} P\left(i, 1, i_{t}^{D}\right)\left\{\sum_{j=0}^{1} P\left(j, 1, d_{t}\right)\left(\sum_{k=0}^{1-j} P\left(k, 1-j, i_{t}^{X}\right) E_{t}\left[\Lambda_{t, t+1}\left[(1+i-j-k) V_{t+1}(1,0)+k V_{t+1}(0,1)\right]\right]\right)\right\} \\
= & E_{t}\left[\Lambda_{t, t+1} V_{t+1}(1,0)\right] \sum_{i=0}^{1} P\left(i, 1, i_{t}^{D}\right) \sum_{j=0}^{1} P\left(j, 1, d_{t}\right) \sum_{k=0}^{1-j} P\left(k, 1-j, i_{t}^{X}\right)(1+i-j-k) \\
& +E_{t}\left[\Lambda_{t, t+1} V_{t+1}(0,1)\right] \sum_{i=0}^{1} P\left(i, 1, i_{t}^{D}\right) \sum_{j=0}^{1} P\left(j, 1, d_{t}\right) \sum_{k=0}^{1-j} P\left(k, 1-j, i_{t}^{X}\right)(k) \\
= & \left(i_{t}^{D}+\left(1-d_{t}\right)\left(1-i_{t}^{X}\right)\right) E_{t}\left[\Lambda_{t, t+1} V_{t+1}(1,0)\right]+\left(1-d_{t}\right) i_{t}^{X} E_{t}\left[\Lambda_{t, t+1} V_{t+1}(0,1)\right]
\end{aligned}
$$

Therefore we have:

$$
\begin{aligned}
V_{t}(1,0)= & \max _{Z_{t}^{D}, Z_{t}^{X}}\left\{\pi_{t}^{D}-Z_{t}^{D}-Z_{t}^{X}\right. \\
& \left.+\left(i_{t}^{D}+\left(1-d_{t}\right)\left(1-i_{t}^{X}\right)\right) E_{t}\left[\Lambda_{t, t+1} V_{t+1}(1,0)\right]+\left(1-d_{t}\right) i_{t}^{X} E_{t}\left[\Lambda_{t, t+1} V_{t+1}(0,1)\right]\right\}
\end{aligned}
$$

Similarly, we can show that the value of a firm with a single exporting line is given as follows:

$$
V_{t}(0,1)=\max _{Z_{t}^{D}}\left\{\pi_{t}^{X}+\pi_{t}^{*}-Z_{t}^{D}+i_{t}^{D} E_{t}\left[\Lambda_{t, t+1} V_{t+1}(1,0)\right]+\left(1-d_{t}\right) E_{t}\left[\Lambda_{t, t+1} V_{t+1}(0,1)\right]\right\}
$$

which is equation (17) and (18) in the main text. Next we work on the value of a firm with general $n^{D}$ domestic lines and $n^{X}$ exporting lines:

$$
\begin{aligned}
V_{t}\left(n^{D}, n^{X}\right)= & \max _{Z_{t}^{D}, Z_{t}^{X}}\left\{n^{D} \pi_{t}^{D}+n^{X}\left(\pi_{t}^{X}+\pi_{t}^{*}\right)-\left(n^{D}+n^{X}\right) Z_{t}^{D}-n^{X} Z_{t}^{X}\right. \\
+ & \sum_{i=0}^{n^{D}+n^{X}} P\left(i, n^{D}+n^{X}, i_{t}^{D}\right) \sum_{j=0}^{n^{D}} P\left(j, n^{D}, d_{t}\right) \sum_{k=0}^{n^{D}-j} P\left(k, n^{D}-j, i_{t}^{X}\right) \sum_{m=0}^{n^{X}} P\left(m, n^{X}, d_{t}\right) \\
& \left.E_{t}\left[\Lambda_{t, t+1} V_{t+1}\left(n^{D}+i-j-k, n^{X}+k-m\right)\right]\right\}
\end{aligned}
$$

Using the linear relation in the value function,

$$
\begin{aligned}
V_{t}\left(n^{D}, n^{X}\right) & =\max _{Z_{t}^{D}, Z_{t}^{X}}\left\{n^{D} \pi_{t}^{D}+n^{X}\left(\pi_{t}^{X}+\pi_{t}^{*}\right)-\left(n^{D}+n^{X}\right) Z_{t}^{D}-n^{D} Z_{t}^{X}\right. \\
& +E_{t}\left[\Lambda_{t, t+1} V_{t+1}(1,0)\right] \sum_{i=0}^{n^{D}+n^{X}} P\left(i, n^{D}+n^{X}, i_{t}^{D}\right) \sum_{j=0}^{n^{D}} P\left(j, n^{D}, d_{t}\right) \sum_{k=0}^{n^{D}-j} P\left(k, n^{D}-j, i_{t}^{X}\right) \sum_{m=0}^{n^{X}} P\left(m, n^{X}, d_{t}\right)\left(n^{D}+i-j-k\right) \\
& +E_{t}\left[\Lambda_{t, t+1} V_{t+1}(0,1)\right] \sum_{i=0}^{n^{D}+n^{X}} P\left(i, n^{D}+n^{X}, i_{t}^{D}\right) \sum_{j=0}^{n^{D}} P\left(j, n^{D}, d_{t}\right) \sum_{k=0}^{n^{D}-j} P\left(k, n^{D}-j, i_{t}^{X}\right) \sum_{m=0}^{n^{X}} P\left(m, n^{X}, d_{t}\right)\left(n^{X}+k-m\right)
\end{aligned}
$$

The second line can be written as follows:

$$
E_{t}\left[\Lambda_{t, t+1} V_{t+1}(1,0)\right]\left(n^{D}+\left(n^{D}+n^{X}\right) i_{t}^{D}-n^{D} d_{t}-n^{D}\left(1-d_{t}\right) i_{t}^{X}\right.
$$


The third line can be written as follows:

$$
E_{t}\left[\Lambda_{t, t+1} V_{t+1}(0,1)\right]\left(n^{X}+n^{D}\left(1-d_{t}\right) i_{t}^{X}-n^{X} d_{t}\right.
$$

Therefore $V_{t}\left(n^{L}, n^{H}\right)$ can be written as follows::

$$
\begin{aligned}
V_{t}\left(n^{D}, n^{X}\right)= & \max _{Z_{t}^{D}, Z_{t}^{X}}\left\{n^{D} \pi_{t}^{D}+n^{X}\left(\pi_{t}^{X}+\pi_{t}^{*}\right)-\left(n^{D}+n^{X}\right) Z_{t}^{D}-n^{D} Z_{t}^{X}\right. \\
& +E_{t}\left[\Lambda_{t, t+1} V_{t+1}(1,0)\right]\left(n^{D}+\left(n^{D}+n^{X}\right) i_{t}^{D}-n^{D} d_{t}-n^{D}\left(1-d_{t}\right) i_{t}^{X}\right. \\
& \left.+E_{t}\left[\Lambda_{t, t+1} V_{t+1}(0,1)\right]\left(n^{X}+n^{D}\left(1-d_{t}\right) i_{t}^{X}-n^{X} d_{t}\right)\right\} \\
= & \max _{Z_{t}^{D}, Z_{t}^{X}}\left\{n^{D} \pi_{t}^{D}+n^{X}\left(\pi_{t}^{X}+\pi_{t}^{*}\right)-\left(n^{D}+n^{X}\right) Z_{t}^{D}-n^{D} Z_{t}^{X}\right. \\
& +n^{D}\left\{\left(i_{t}^{D}+\left(1-d_{t}\right)\left(1-i_{t}^{X}\right)\right) E_{t}\left[\Lambda_{t, t+1} V_{t+1}(1,0)\right]+\left(1-d_{t}\right) i_{t}^{X} E_{t}\left[\Lambda_{t, t+1} V_{t+1}(0,1)\right]\right\} \\
& \left.+n^{X}\left\{i_{t}^{D} E_{t}\left[\Lambda_{t, t+1} V_{t+1}(1,0)\right]+\left(1-d_{t}\right)\right\} E_{t}\left[\Lambda_{t, t+1} V_{t+1}(0,1)\right]\right\} \\
= & n^{D} V_{t}(1,0)+n^{X} V_{t}(0,1)
\end{aligned}
$$

This verifies that the initial guess $V_{t}\left(n^{D}, n^{X}\right)=n^{D} V_{t}(1,0)+n^{X} V_{t}(0,1)$ is correct.

\section{A.4 Firm Size Distribution}

This section shows the law of motion for the share of each firm size and how to derive the firm size distribution. Each firm is characterized by the number of domestic and exporting lines it owns, $\left(n^{D}, n^{X}\right)$. The law of motion for the firm size $\left(n^{D}, n^{X}\right)$ is the formula that gives us the measure (number) of firms that own $\left(n^{D}, n^{X}\right)$ given the firm size distribution in the previous period. Let $\delta_{t}\left(n^{D}, n^{X}\right)$ denote the measure of firms that own $n^{D}$ domestic lines and $n^{X}$ exporting lines at period $t$. Because the total measure of intermediate goods is one and each firm owns at least one product line, the measure of firms is between 0 and 1, i.e. $\delta_{t}\left(n^{D}, n^{X}\right) \in[0,1] \forall t, n^{D}, n^{X}$. In order for a firm to become a firm with $\left(n^{D}, n^{X}\right)$ in the next period, there are some conditions to be satisfied. For example, a firm with $(i, j)$ at period $t-1$ can own at most $2 i+j$ domestic lines, because this is the case in which all domestic innovations $(i+j)$ are successful, all exporting innovations fail, and no replacement on domestic lines happens. So, if a firm owns $(i, j)$ that satisfies $2 i+j<n^{D}$, this firm cannot become a firm with $\left(n^{D}, n^{X}\right)$ in the next period.

Let $(i, j)$ denote the number of domestic and exporting lines that a firm owns at period $t-1$. Let $(k, m)$ denote the number of successes in domestic innovation and exporting innovation respectively. Then consider a case in which this firm becomes a firm with $\left(n^{D}, n^{X}\right)$. This implies that the number of replacement on domestic and exporting lines, denoted by $\left(r^{D}, r^{X}\right)$, are given by $r^{D}=i+k-m-n^{D}$ and $r^{X}=j+m-n^{X}$. The table below lists up all the notations: 


\begin{tabular}{c|c}
\hline symbol & description \\
\hline \hline$n^{D}$ & domestic lines next period \\
\hline$n^{X}$ & exporting lines next period \\
\hline$i$ & domestic lines this period \\
\hline$j$ & exporting lines this period \\
\hline$k$ & successes in domestic innovation \\
\hline$m$ & successes in exporting innovation \\
\hline$r^{D}$ & replacements on domestic lines \\
\hline$r^{X}$ & replacements on exporting lines \\
\hline
\end{tabular}

These variables need to satisfy the following conditions:

- Number of successful innovations is limited by the number of existing lines:
(1) $k \leq i+j$
(2) $m \leq i$

- The sum of exporting innovation and replacements on domestic lines is limited by the number of existing domestic lines. The number of replacements on exporting lines is limited by the number of existing exporting lines:

(3) $r^{D}+m \leq i$

(4) $r^{X} \leq j$

- Minimum necessary number of successful innovations to achieve $\left(n^{D}, n^{X}\right)$ :

(5) $k \geq n^{D}-i$

(6) $m \geq n^{X}-j$

- Given $i$, minimum necessary number of exporting lines $j$ to achieve $\left(n^{D}, n^{X}\right)$ :

(7) $j \geq n^{D}-2 j$

(8) $j \geq n^{X}-i$

- Non-negativity constraints: 
(9) $i \geq 0$

(10) $j \geq 0$

(11) $k \geq 0$

(12) $m \geq 0$

(13) $r^{D} \geq 0$

(14) $r^{X} \geq 0$

As in the main text, let $P(i, n, p)$ denote the binomial probability for $i$ successes in $n$ trials with the success probability $p$. Incorporating all the conditions above and some additional conditions to keep the consistency across different conditions, the law of motion for firm size $\left(n^{D}, n^{X}\right)$ is given as follows:

$$
\begin{aligned}
\delta_{t}\left(n^{D}, n^{X}\right)= & \sum_{i=0}^{\infty} \sum_{j=\max \left\{\begin{array}{c}
0, n^{D}-2 i, \\
n^{X}-i, I_{+}\left(\frac{n^{D}+n^{X}}{2}-i\right)
\end{array}\right\}}^{\infty} \delta_{t-1}(i, j) \sum_{k=\max \left\{\begin{array}{c}
0, n^{D}-i, \\
n^{D}+n^{X}-j
\end{array}\right.}^{\min \left\{n^{D}, i+j\right\}} \sum^{m=\max \left\{0, n^{X}-j\right\}} \\
& P\left(k, i+j, i_{t}^{D}\right) P\left(m, n^{D}+m-k, i_{t}^{X}\right) P\left(i+k-n^{D}-m, i, d_{t}\right) P\left(j+m-n^{X}, j, d_{t}\right)
\end{aligned}
$$

where $I_{+}(x)$ is the smallest integer that is equal to or greater than $x$. The special case is $\left(n^{D}, n^{X}\right)=(1,0)$, because there is new firm entry. In this case $e_{t}$ is added to the right-hand side.

To derive the firm-size distribution at the balanced growth path, we use the values at the balanced growth path for new entry, innovation and replacement rates $e_{t}, i_{t}^{D}, i_{t}^{X}, d_{t}$, and iterate this law of motion for large enough $\left(n^{D}, n^{X}\right)$ until the distribution converges for every firm size. The result is reported in Figure 3 in the main text.

\section{A.5 Sudden Stops, Welfare and Productivity}

Finally, we simulate counterfactuals to determine to what extent the growth and trade dynamics account for the welfare loss caused by sudden stops. We conduct the following simulations: we set the initial state of the economy as the average state one period before sudden stops happen in the previous simulation. Then we create two economies with different shocks: in the first economy, we feed a good shock of high TFP and low interest rate at period 1. In the second economy, we feed a bad shock of low TFP and high interest rate at period 1. In this second economy, a sudden stop happens at period 1 because we set the initial state as such, while in the first economy a sudden stop does not happen at period 1. For the following periods, we feed the same random shocks to both economies, following a good shock at period 1. In this way, we create two artificial economies for which the only difference is whether a sudden stop 
happens at period 1 or not. Thus we call the first economy the no-SS economy, and the second economy the SS economy henceforth. We simulate these two economies many times with stochastic shocks from period 2 onwards, and compare the average productivity paths and expected welfare. This analysis tells us the average productivity loss and welfare loss by a sudden stop.

We also simulate the counterfactual economies to disentangle the effects of the growth and trade dynamics on productivity and welfare. For the first counterfactual economy, we take the path of the productivity growth rate $g_{t}$ from the no-SS economy and feed them into the SS economy. In this economy, a sudden stop happens at period 1, but it does not affect productivity at all. For the second counterfactual, we take the domestic innovation rate $i_{t}^{D}$ from the no-SS economy and feed it into the SS economy to see how much the domestic innovation rate accounts for the productivity loss and the welfare loss. For the third counterfactuall, we do the same for the exporting innovation rate.

Figure 8: Decomposition of Productivity Dynamics

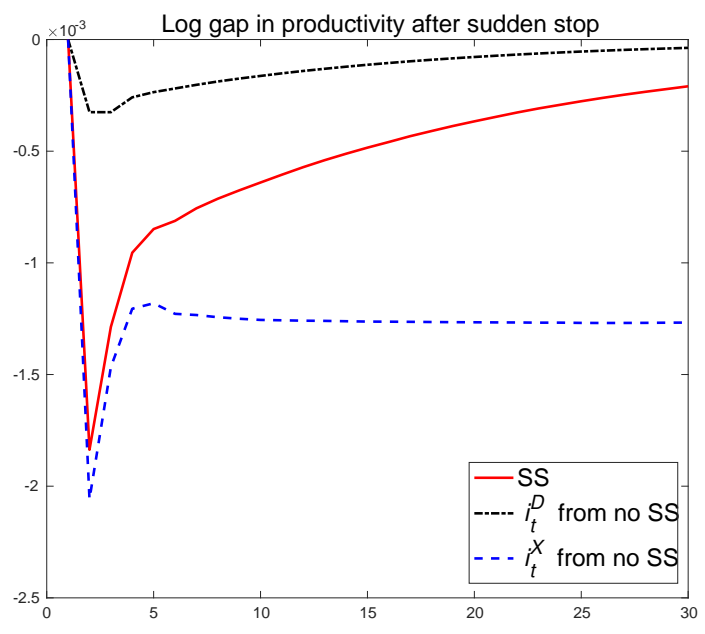

Figure 8 and Table 7 summarize the results. The main results are as follows. First, the red solid line in Figure 8 shows that the productivity level drops by $0.18 \%$ on impact of a sudden stop compared to the no-SS economy, and recovery takes a very long time. The average welfare loss by a sudden stop is $0.068 \%$ in terms of permanent consumption as shown in Table 7.

Second, if the productivity growth rate is not affected by a sudden stop at all, then the welfare loss reduces to $-0.042 \%$ of permanent consumption. This means that about $38 \%$ of a welfare loss by a sudden stop is accounted for by the productivity loss.

Third, if we take the domestic innovation rate from the no-SS economy and feed it into the SS economy, then the productivity level barely declines compared to the no-SS economy, as shown by the black 
Table 7: Decomposition of Welfare Effects

\begin{tabular}{cc}
\hline Economy & Welfare loss \\
\hline \hline Total cost of Sudden Stop & $-0.068 \%$ \\
\hline$g_{t}$ from no SS & $-0.042 \%$ \\
\hline$i_{t}^{D}$ from no SS & $-0.046 \%$ \\
\hline$i_{t}^{X}$ from no SS & $-0.107 \%$ \\
\hline
\end{tabular}

dotdash line in 8 . This means that most of the productivity loss by a sudden stop comes from drops in the domestic innovation rate. Consistent with this result, the welfare loss in this economy is very close to the case of no productivity loss, $-0.046 \%$ compared to $-0.042 \%$.

Fourth, if we do the same analysis on the exporting innovation rate, then the productivity level never catches up the level of the no-SS economy, as shown by the blue dotted line in 8 . This result is understood as follows: when a sudden stop happens, productivity growth slows down and the productivity level declines persistently compared to the case without a sudden stop, as shown in 8 . This lower productivity gives a cost advantage for exporters, which induces more exporting innovation. This active exporting innovation is the driver of the productivity recovery. Taking the exporting innovation rate from the no-SS economy shuts off this channel, and the productivity level never catches up the original trend. In this case, the welfare loss increases to $-0.107 \%$. This means that boosting exporting innovation through a cost advantage after sudden stops reduces the welfare cost of sudden stops substantially by about $36 \%$. 